\title{
Cyclopropyl thioethers, new inputs for Palladium catalyzed ring-opening of cyclopropanes
}

Sudipta Ponra, ${ }^{\ddagger}$ Aude Nyadanu, ${ }^{\ddagger}$ Na Pan, ${ }^{\dagger}$ Elodie Martinand-Lurin, ${ }^{\dagger}$ Alexandra Savy ${ }^{\dagger}$

Maxime Vitale, ${ }^{\ddagger}$ Laurent El Kaim ${ }^{*}$ and Laurence Grimaud. †*

NMR Spectra

(2-Bromophenyl)(cyclopropyl)sulfane (1a): 

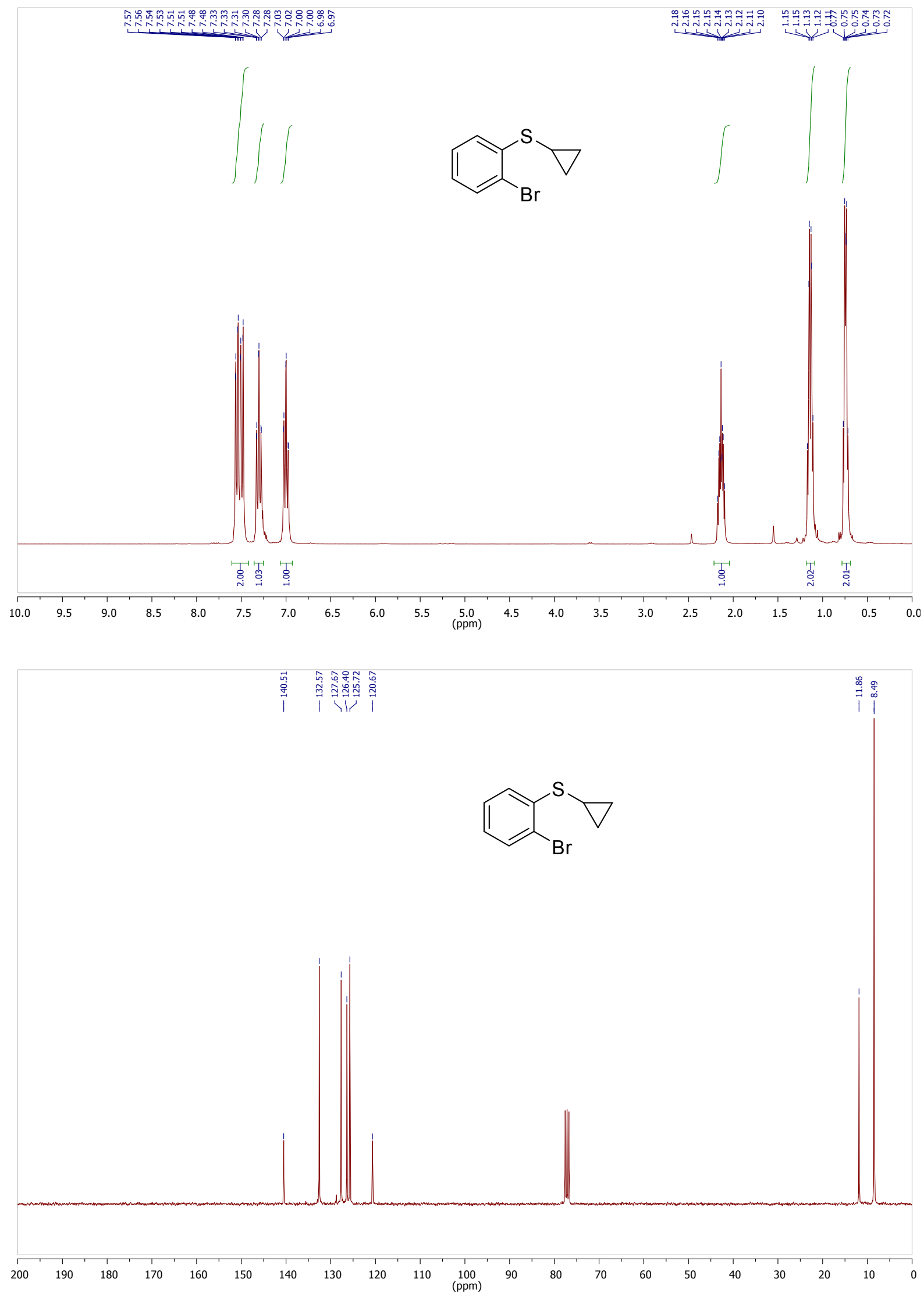
(2-Bromo-5-chlorophenyl)(cyclopropyl)sulfane (1b) 


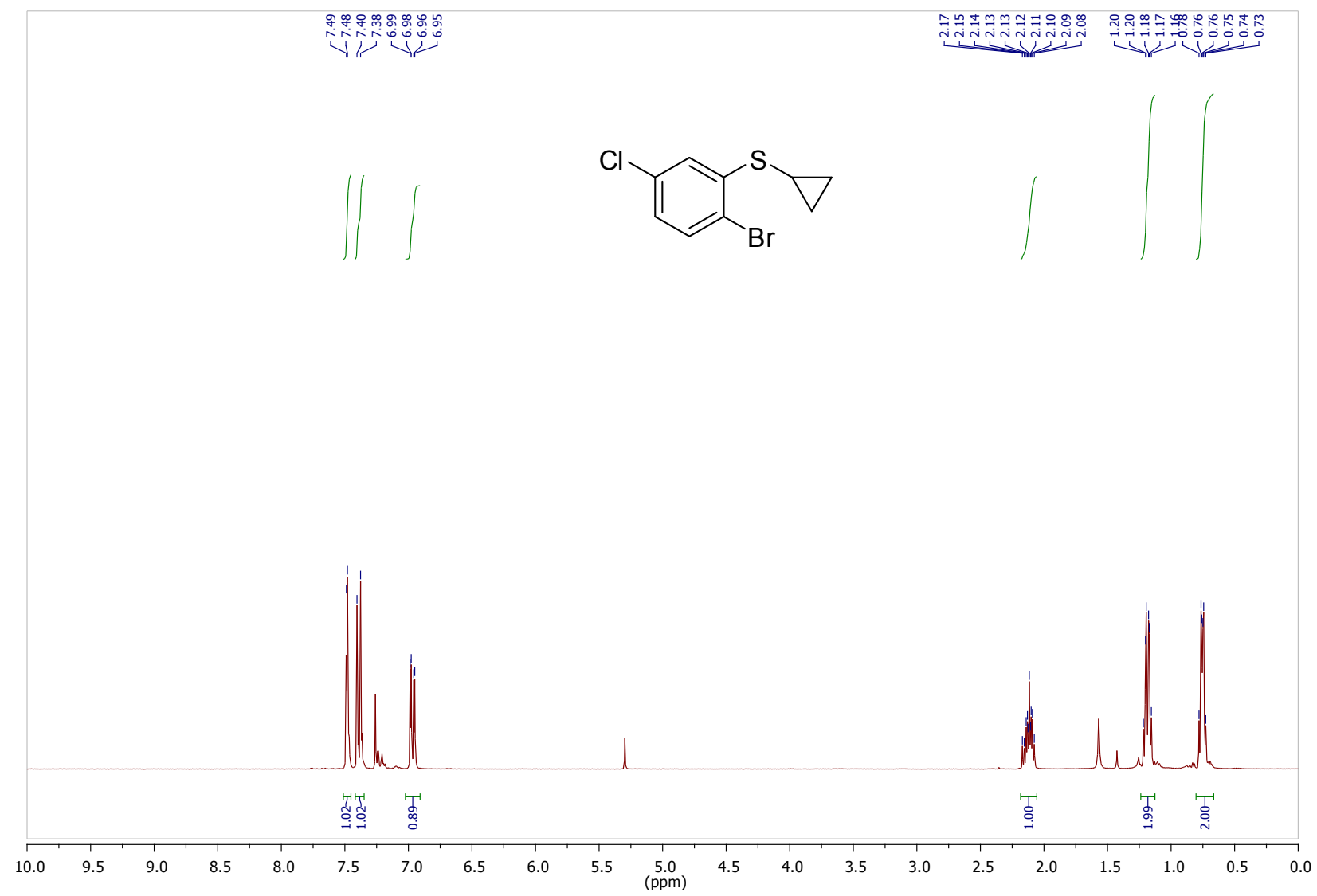




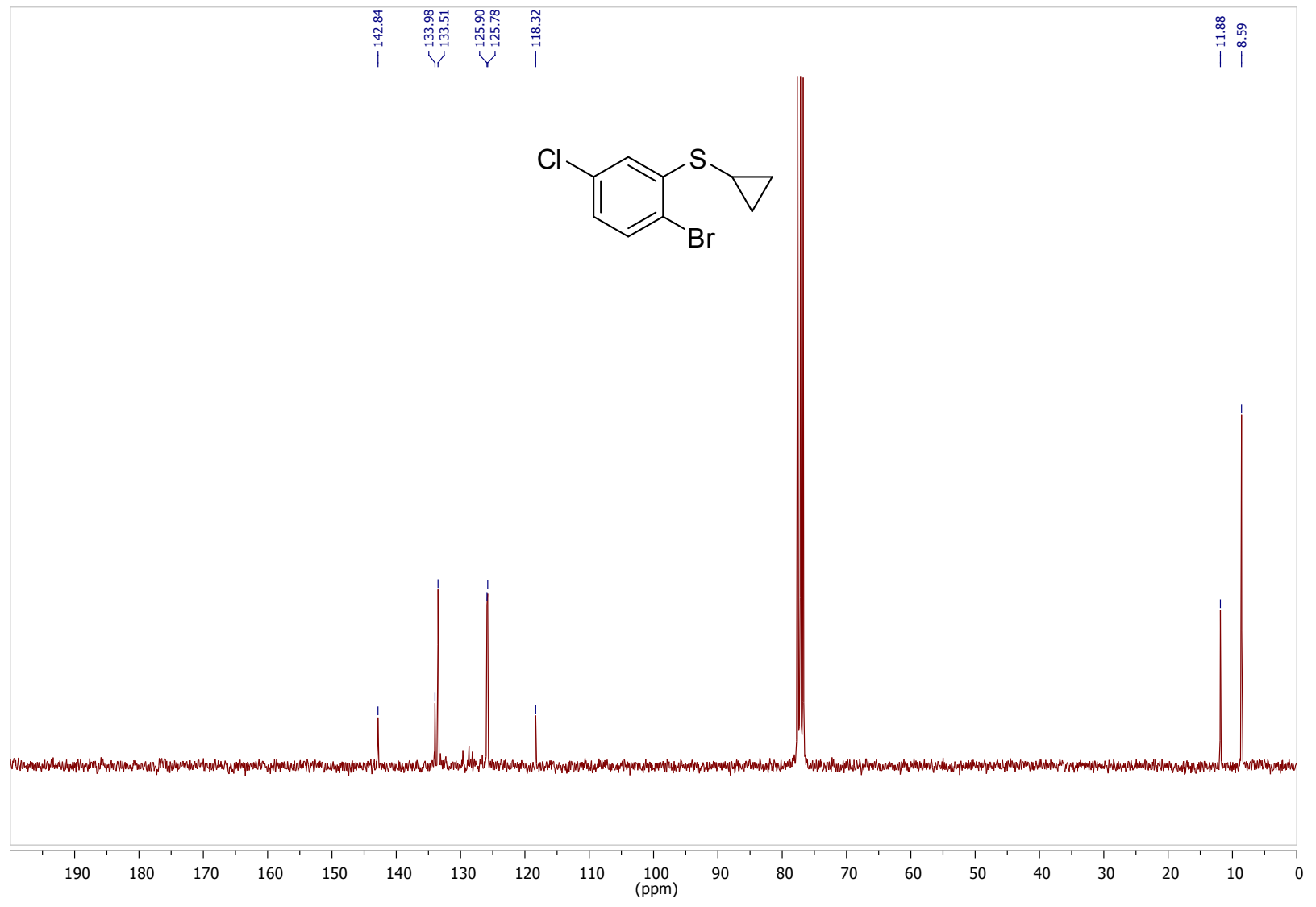


1-(3-Bromo-4-(cyclopropylthio)phenyl)ethanone (1c):

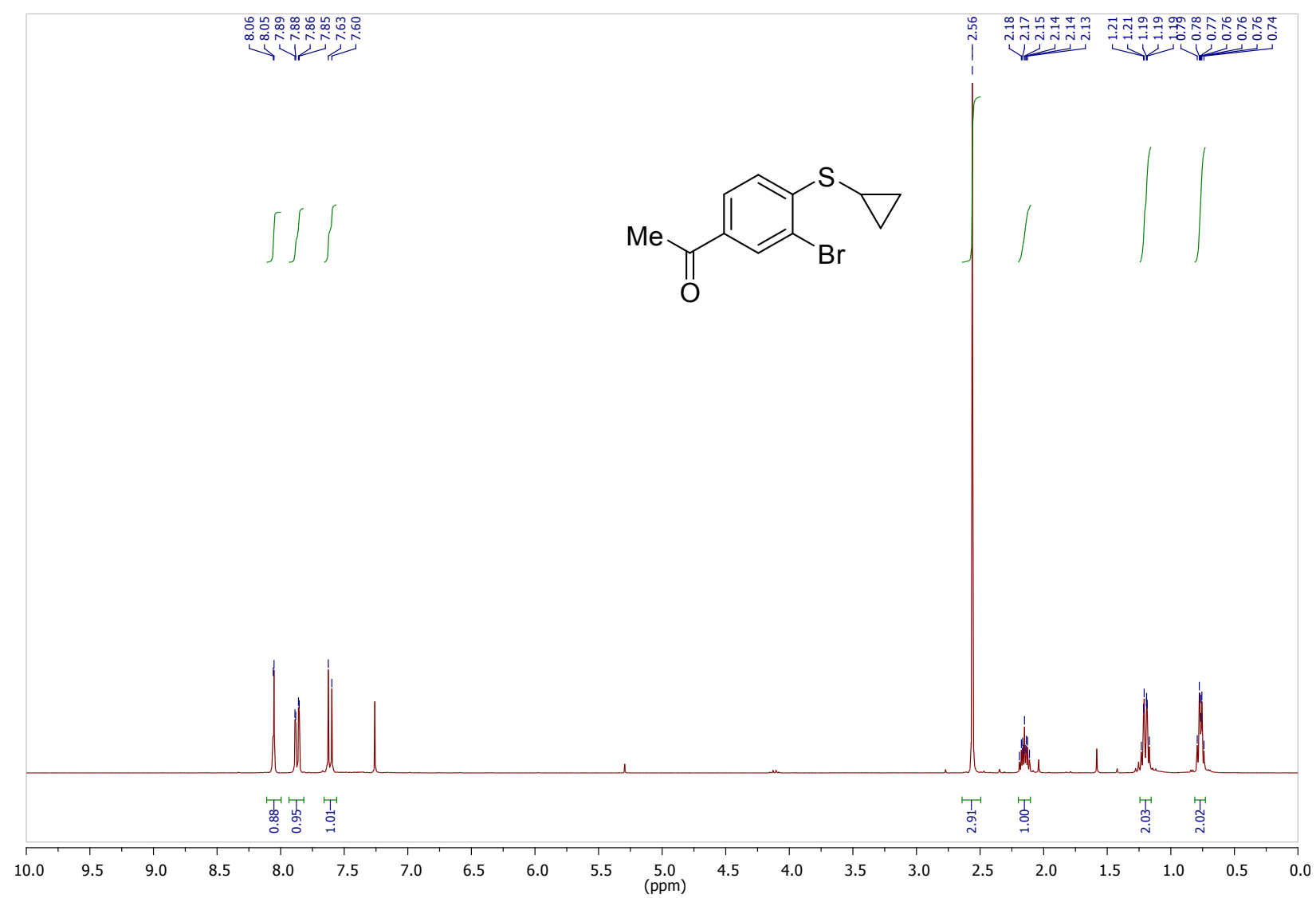




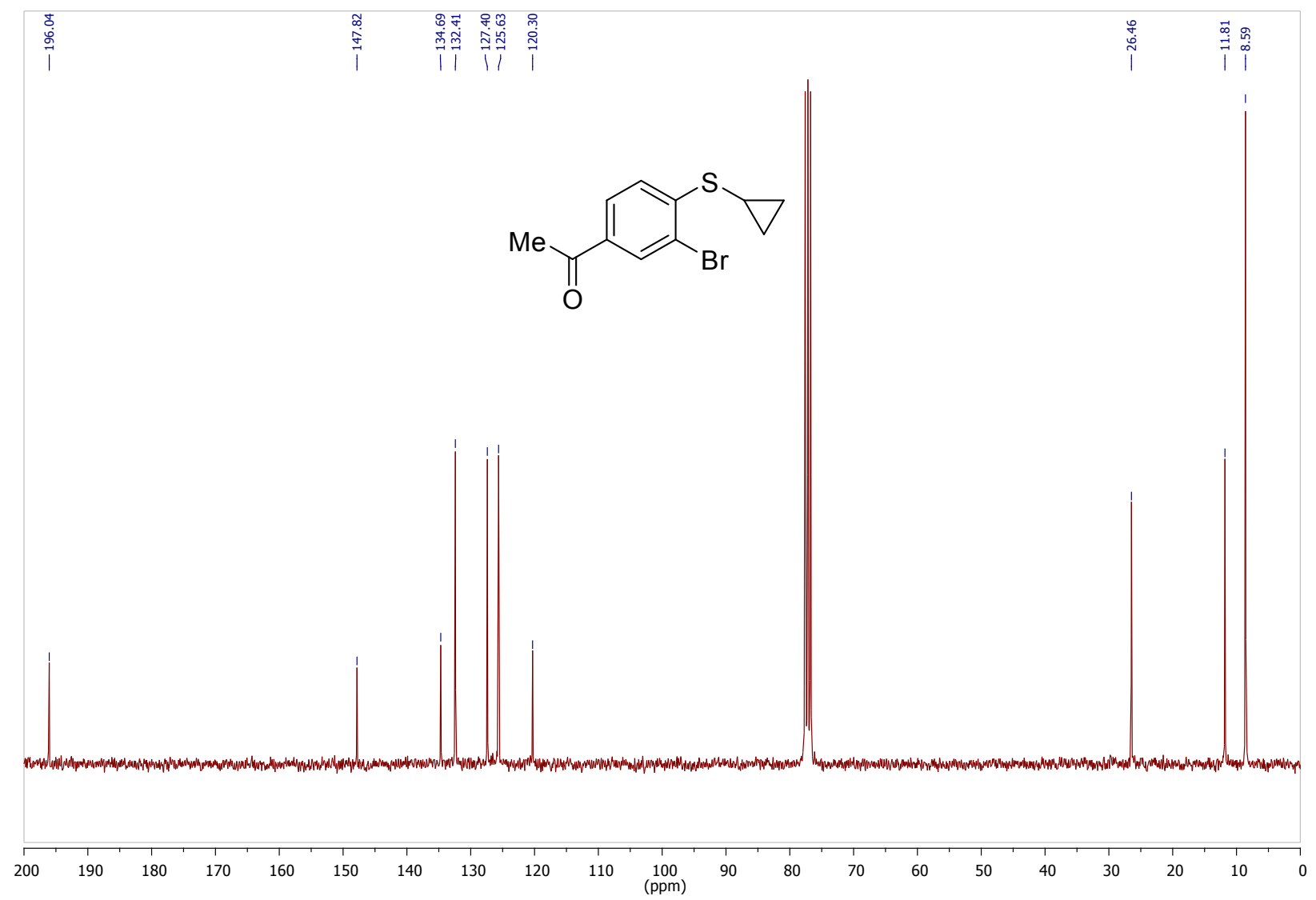


1-(3-Bromo-4-(cyclopropylthio)phenyl)-2-phenylethanone (1d):

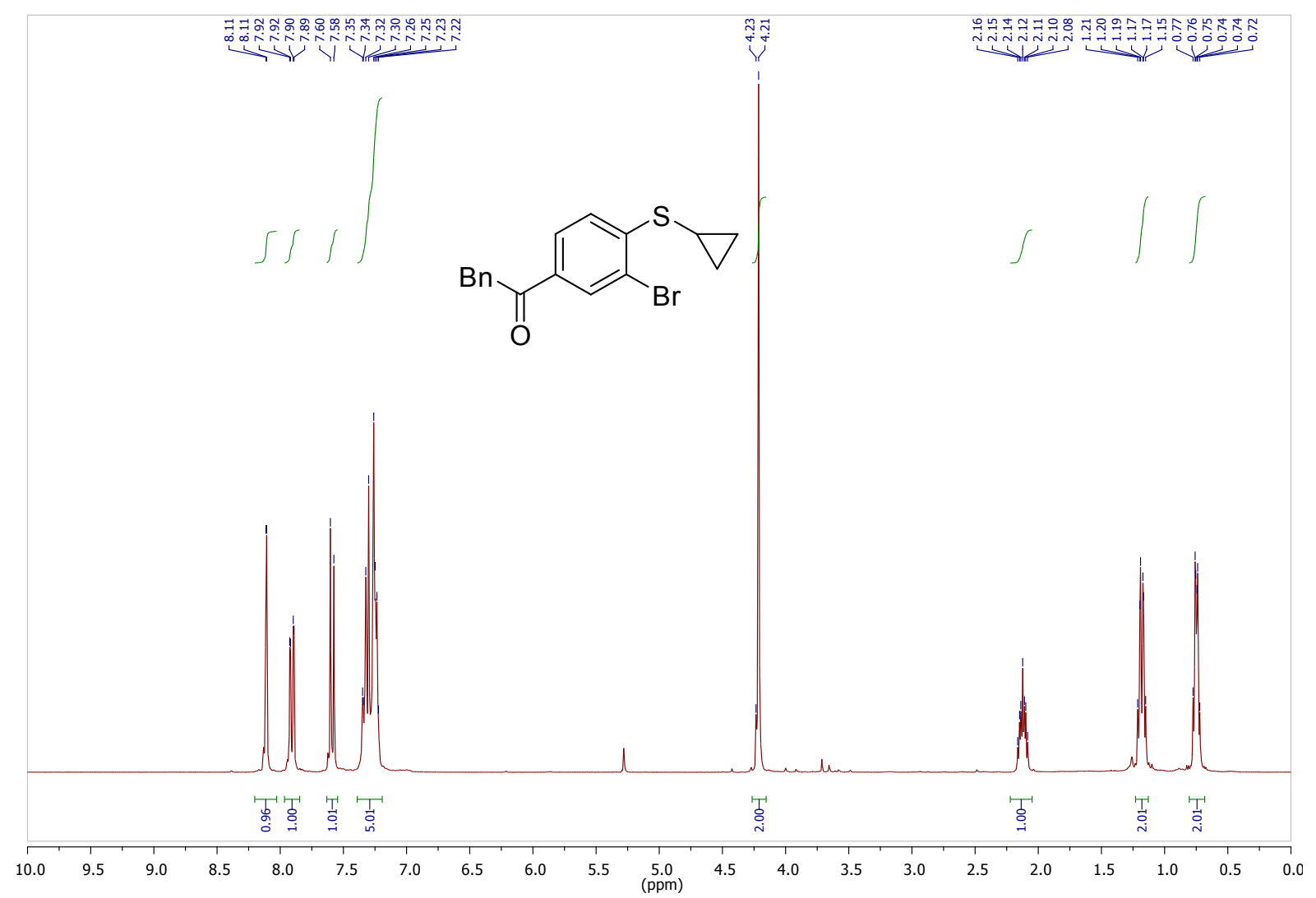




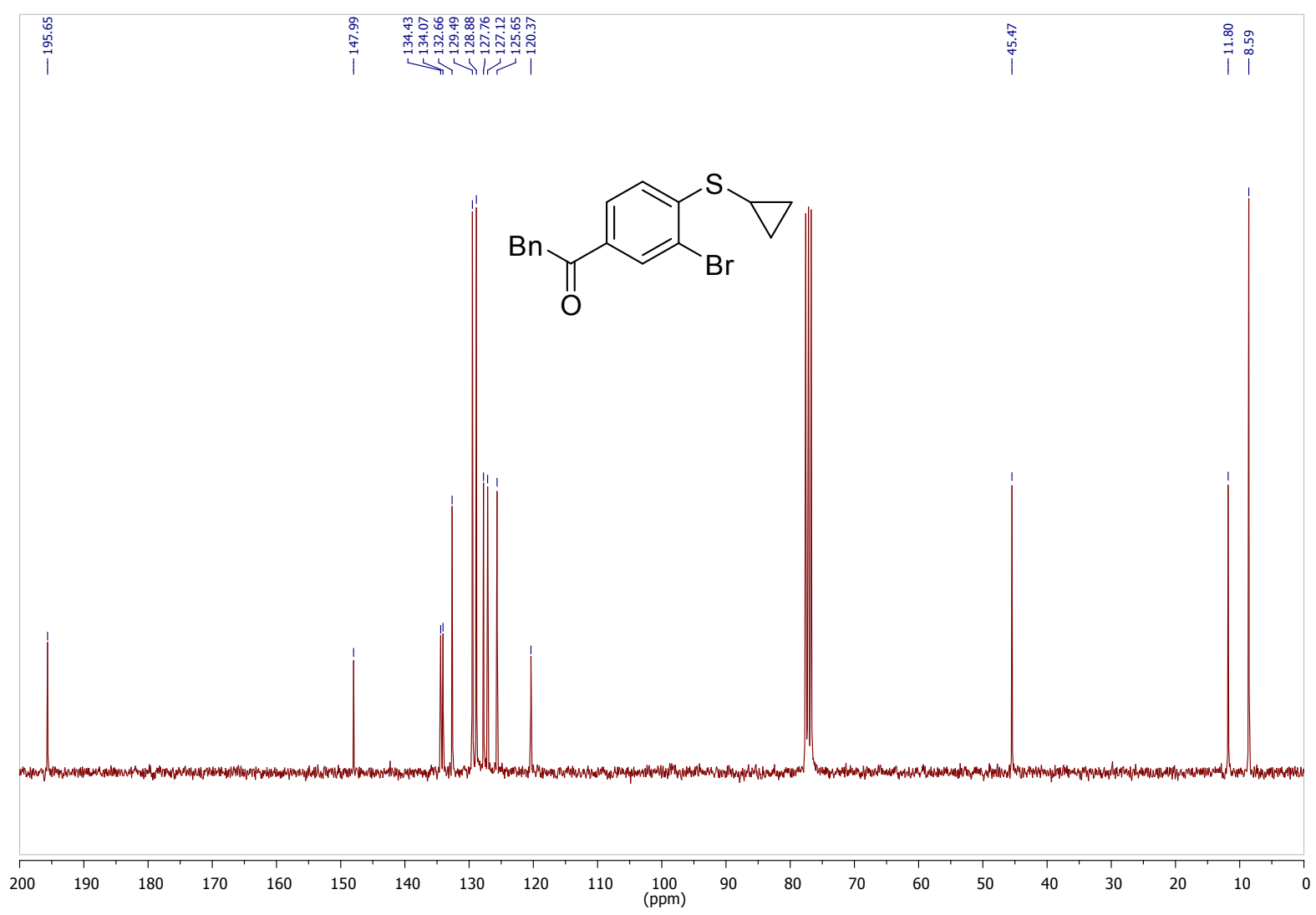




\section{Cyclopropyl(p-tolyl)sulfane:}
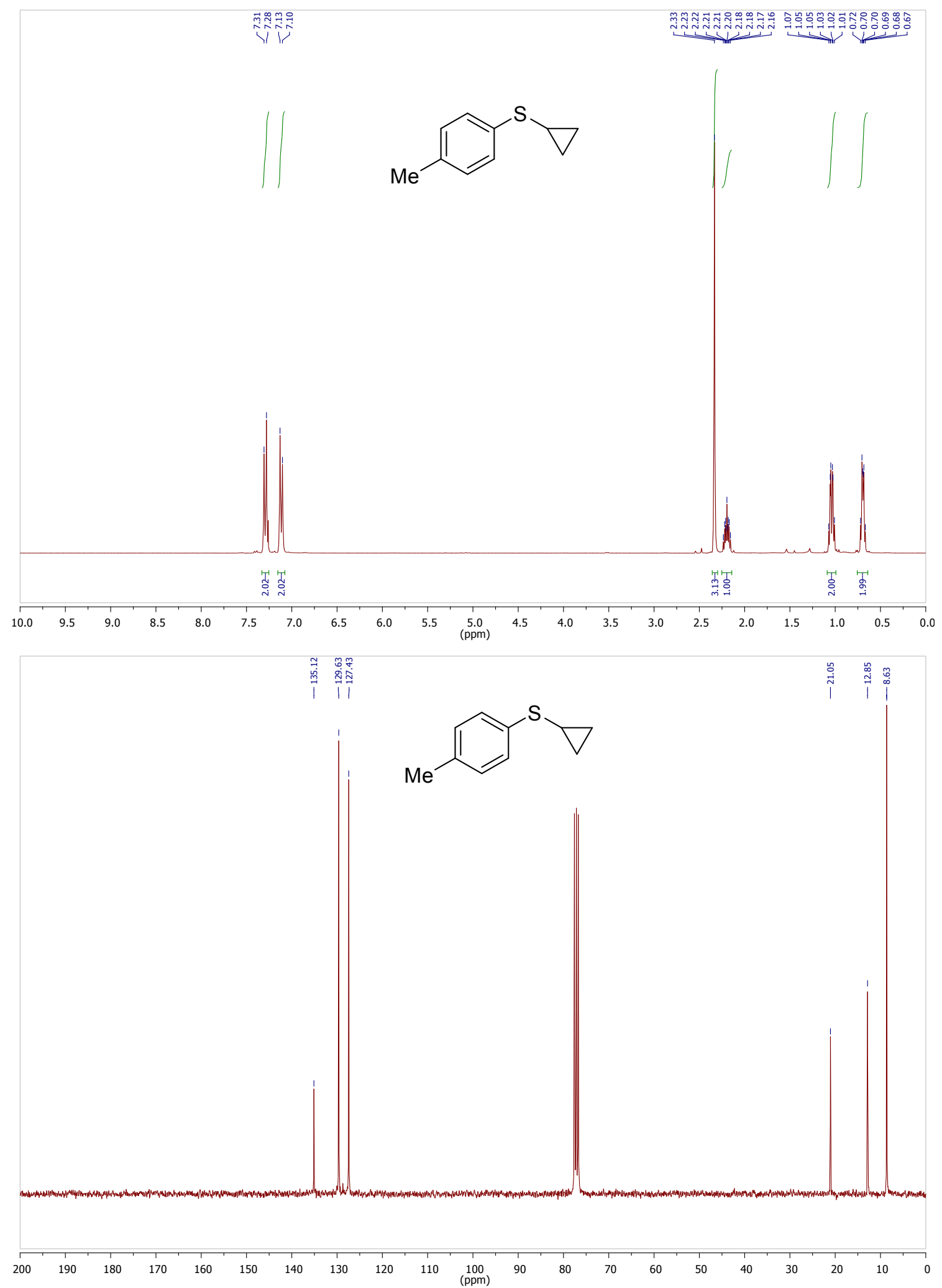


\section{(2-Bromo-4-methylphenyl)(cyclopropyl)sulfane (1e):}

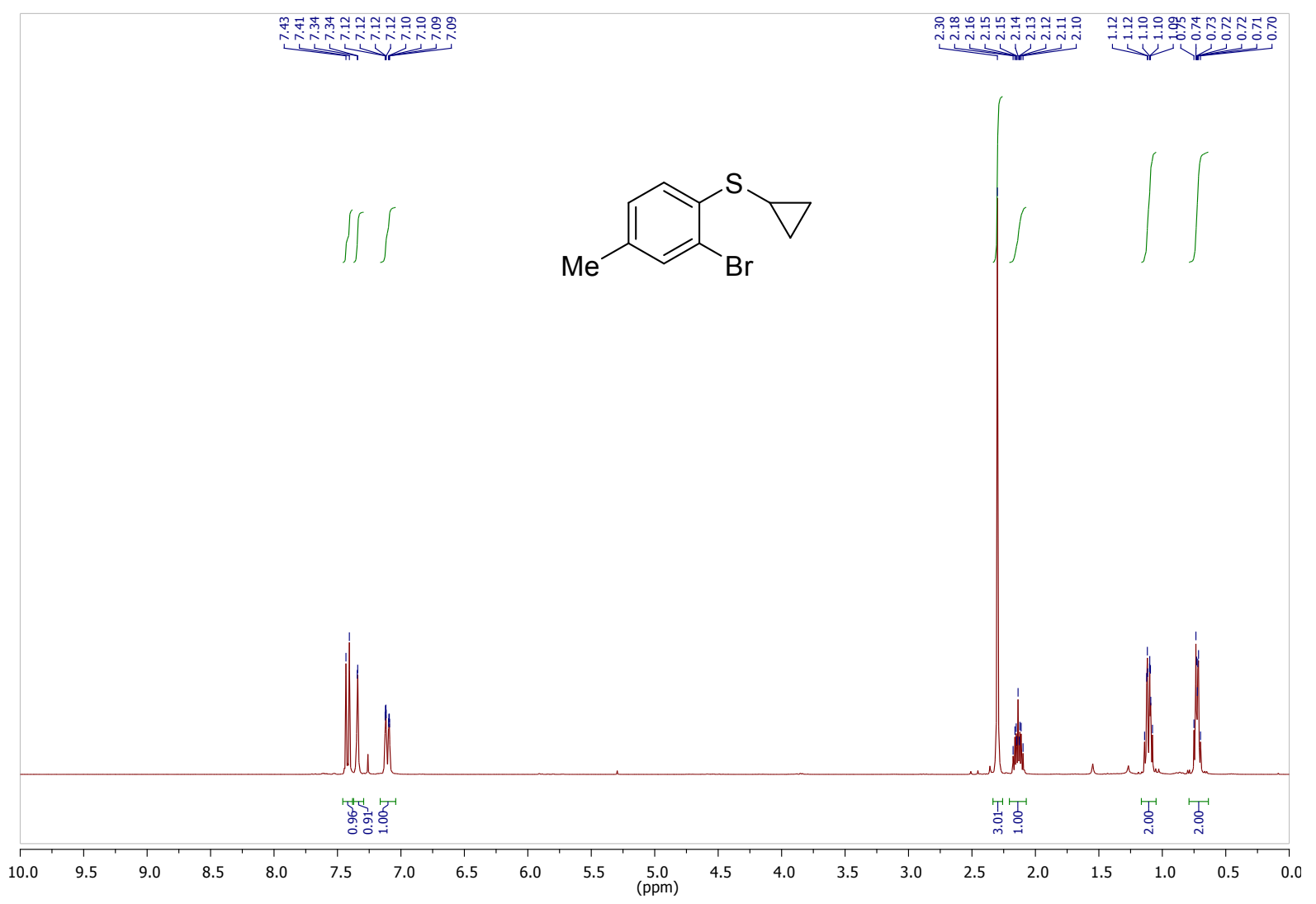




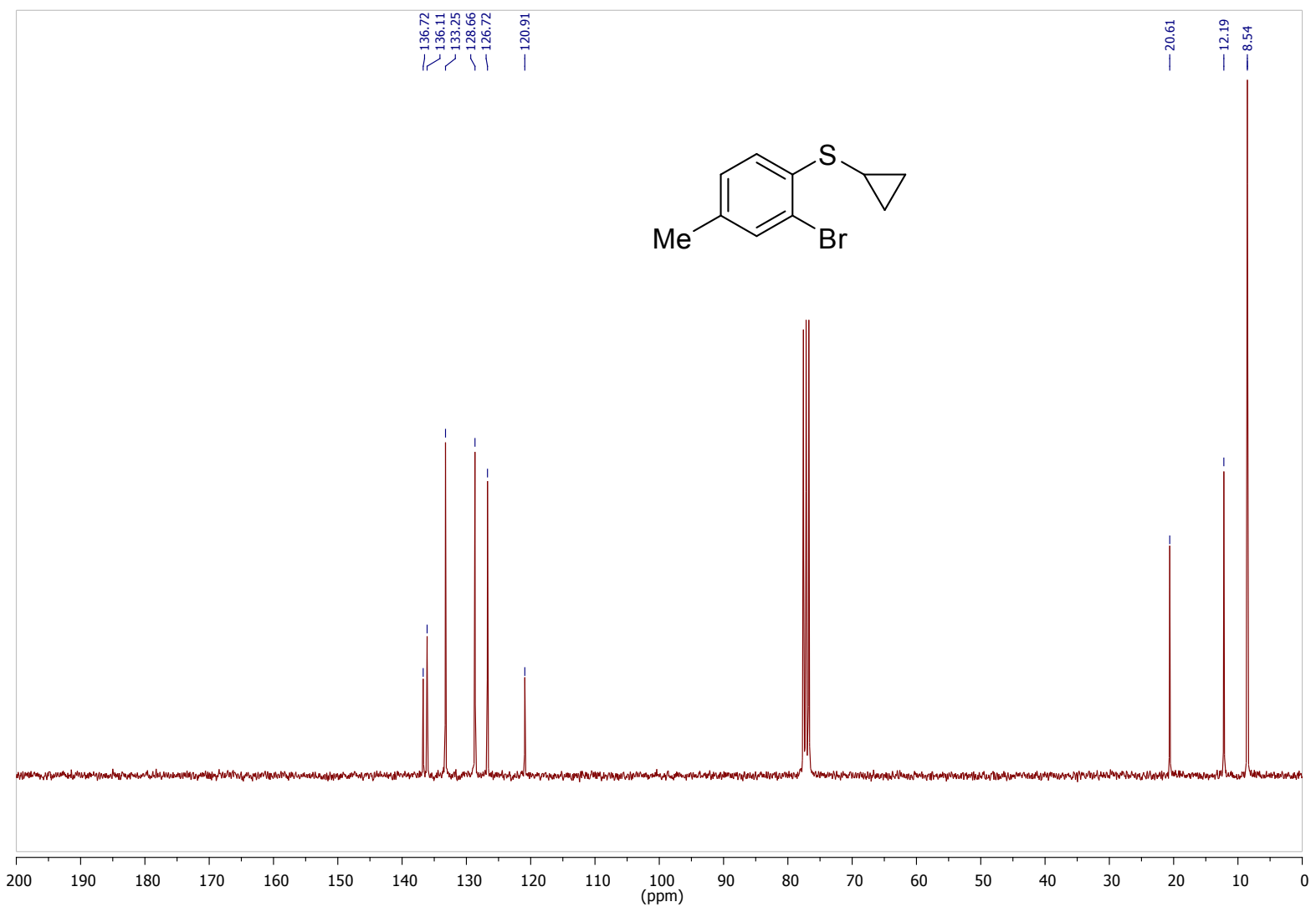


(2-Bromo-4-ethylphenyl)(cyclopropyl)sulfane (1f):

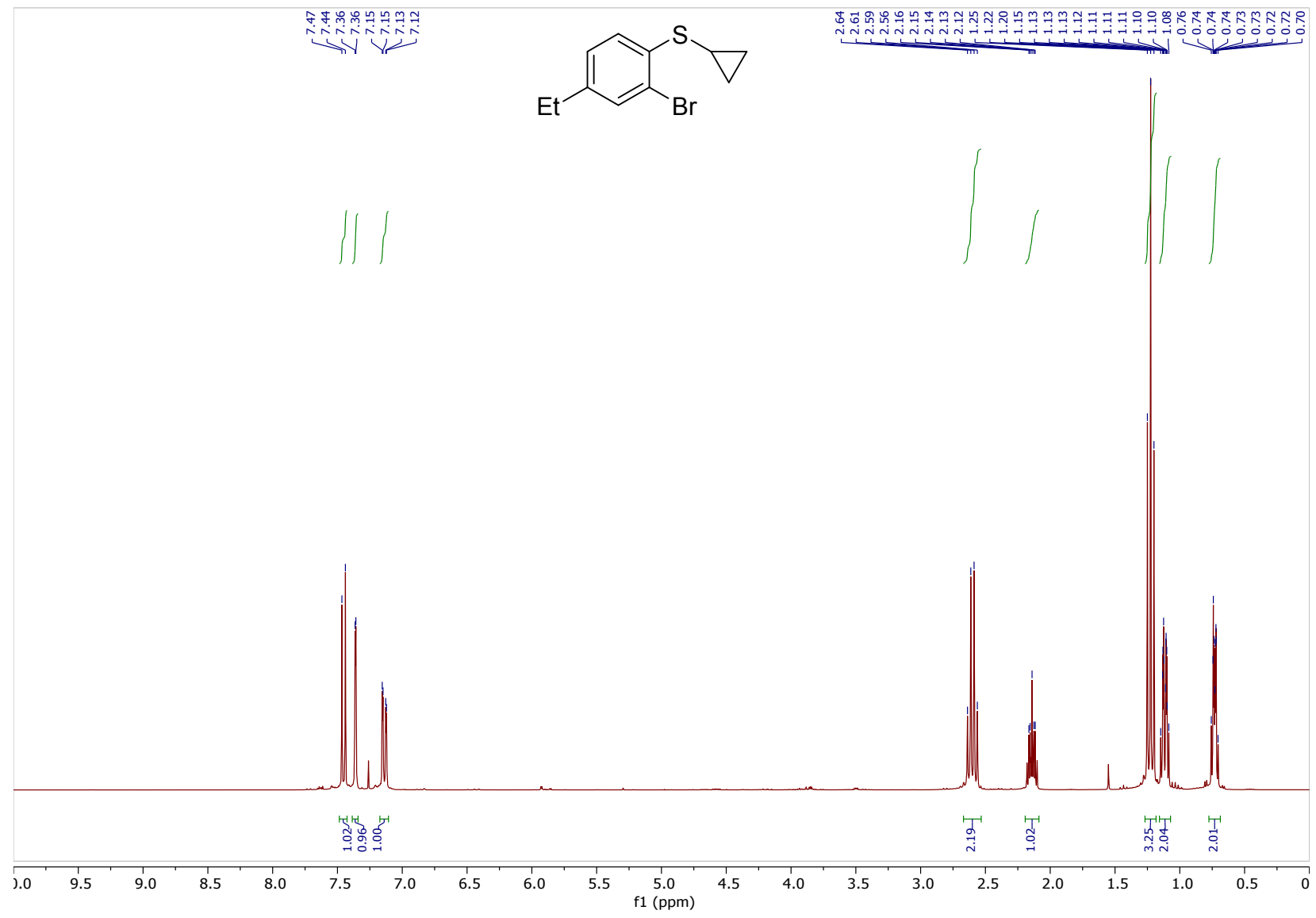




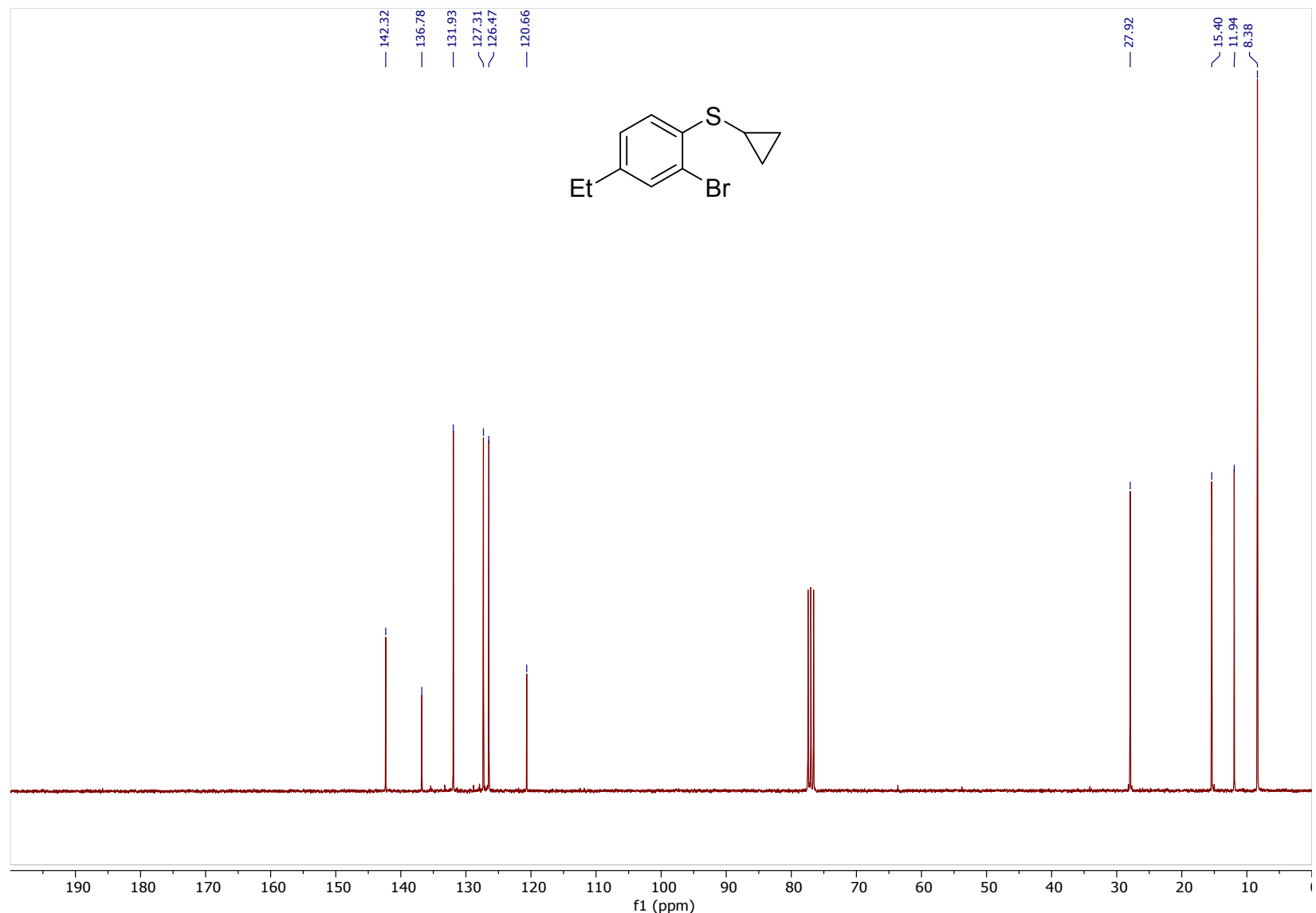


(2-Bromo-4-isopropylphenyl)(cyclopropyl)sulfane (1g):

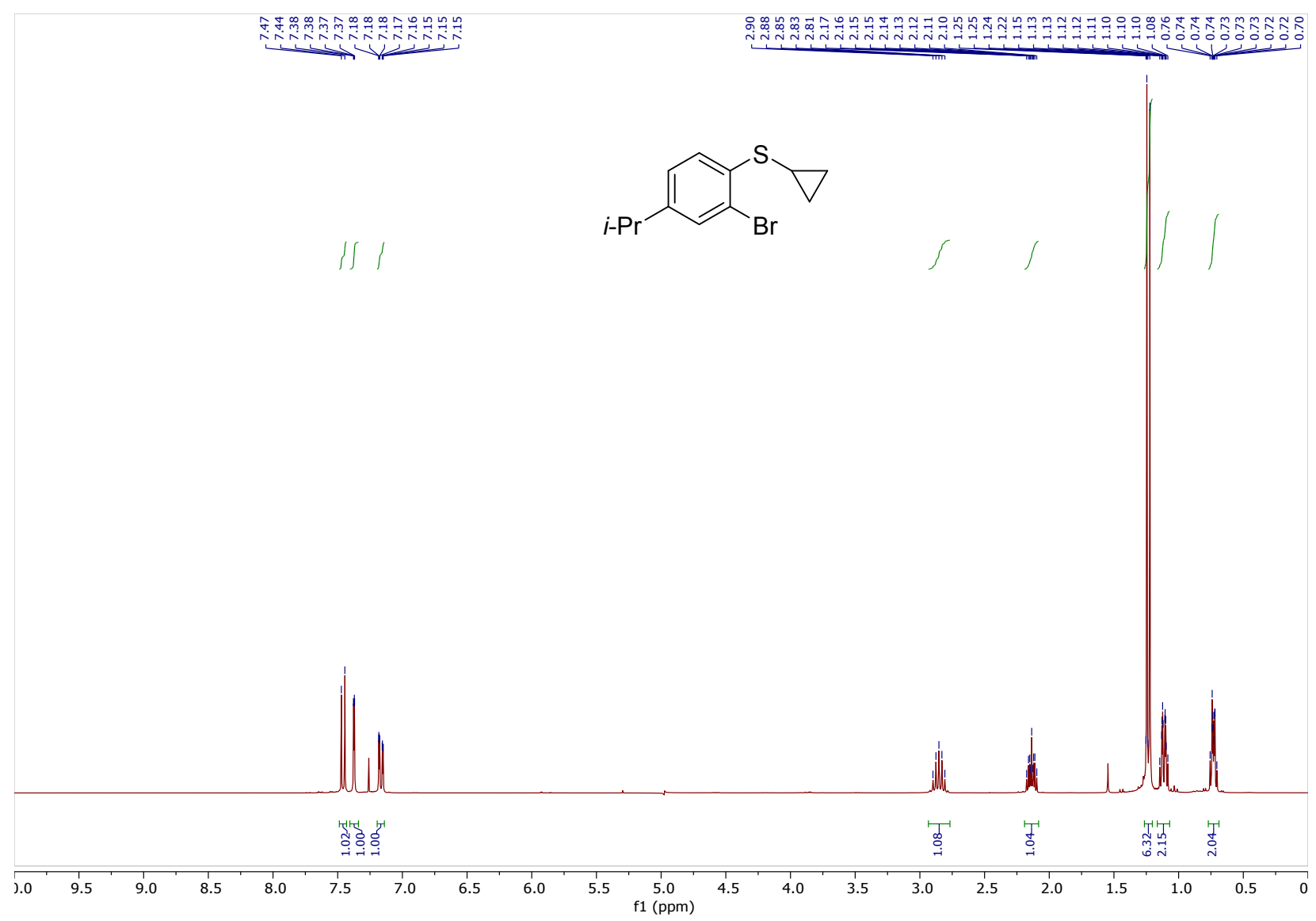




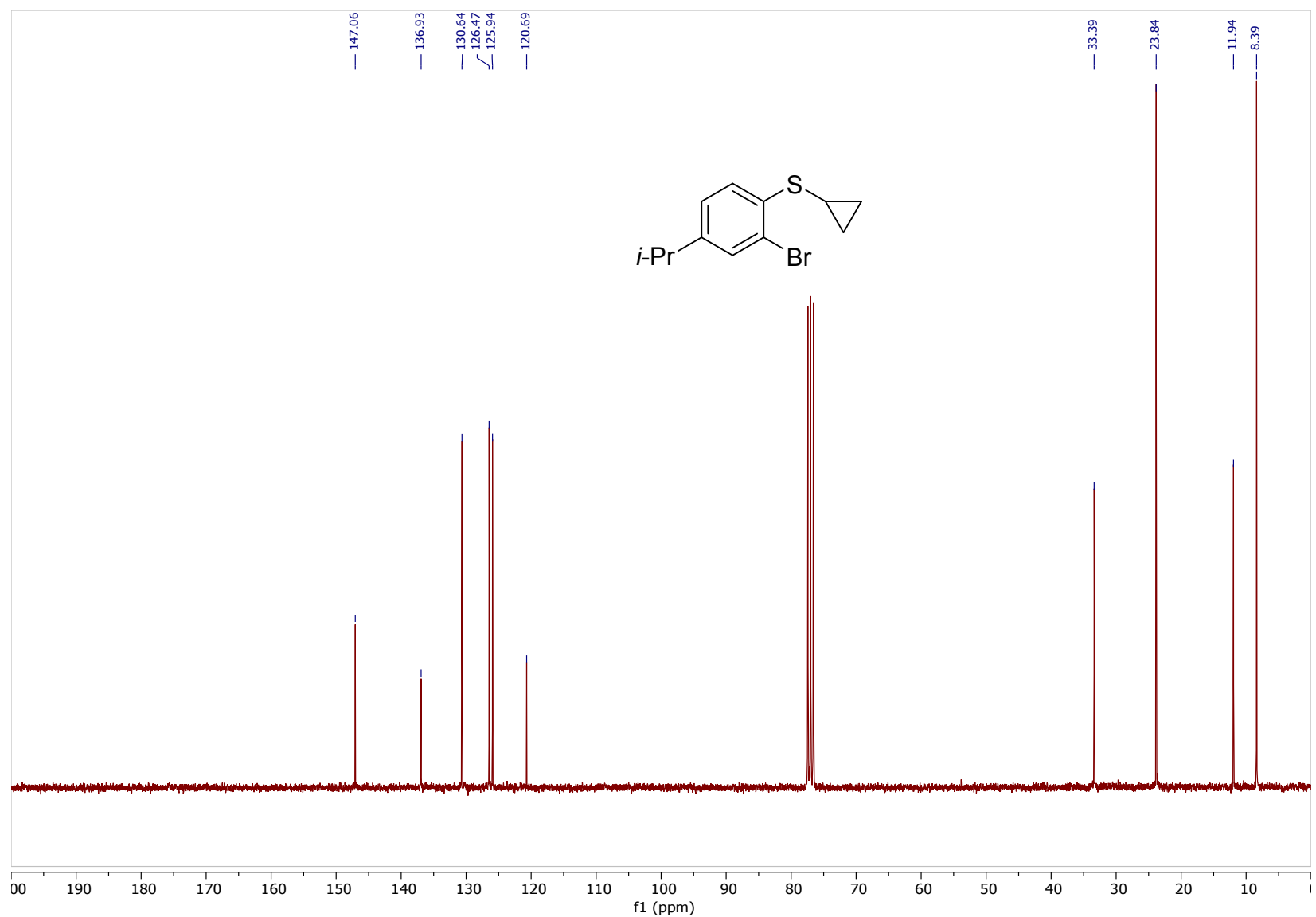




\section{(4-tert-Butylphenyl)(cyclopropyl)sulfane:}

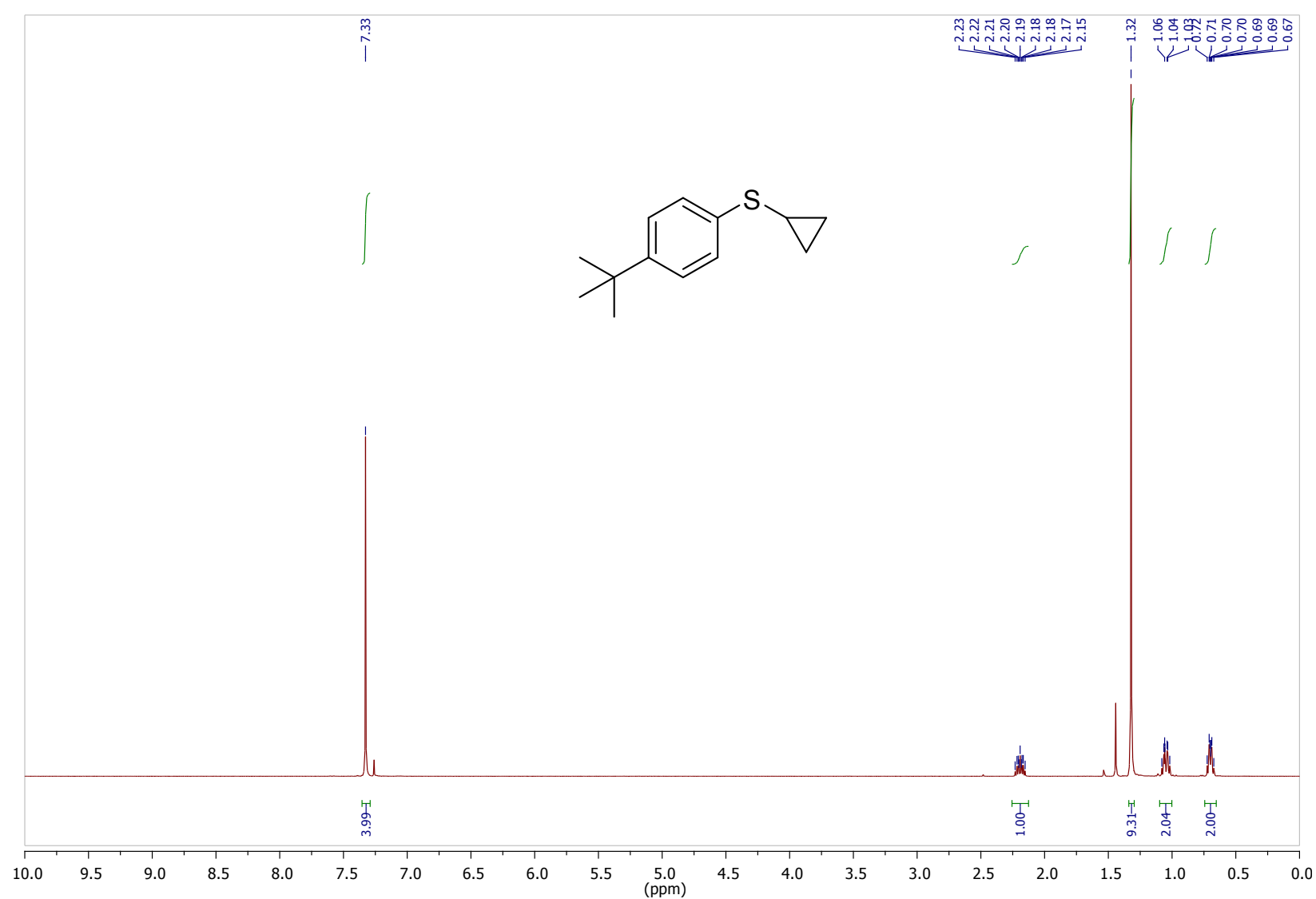




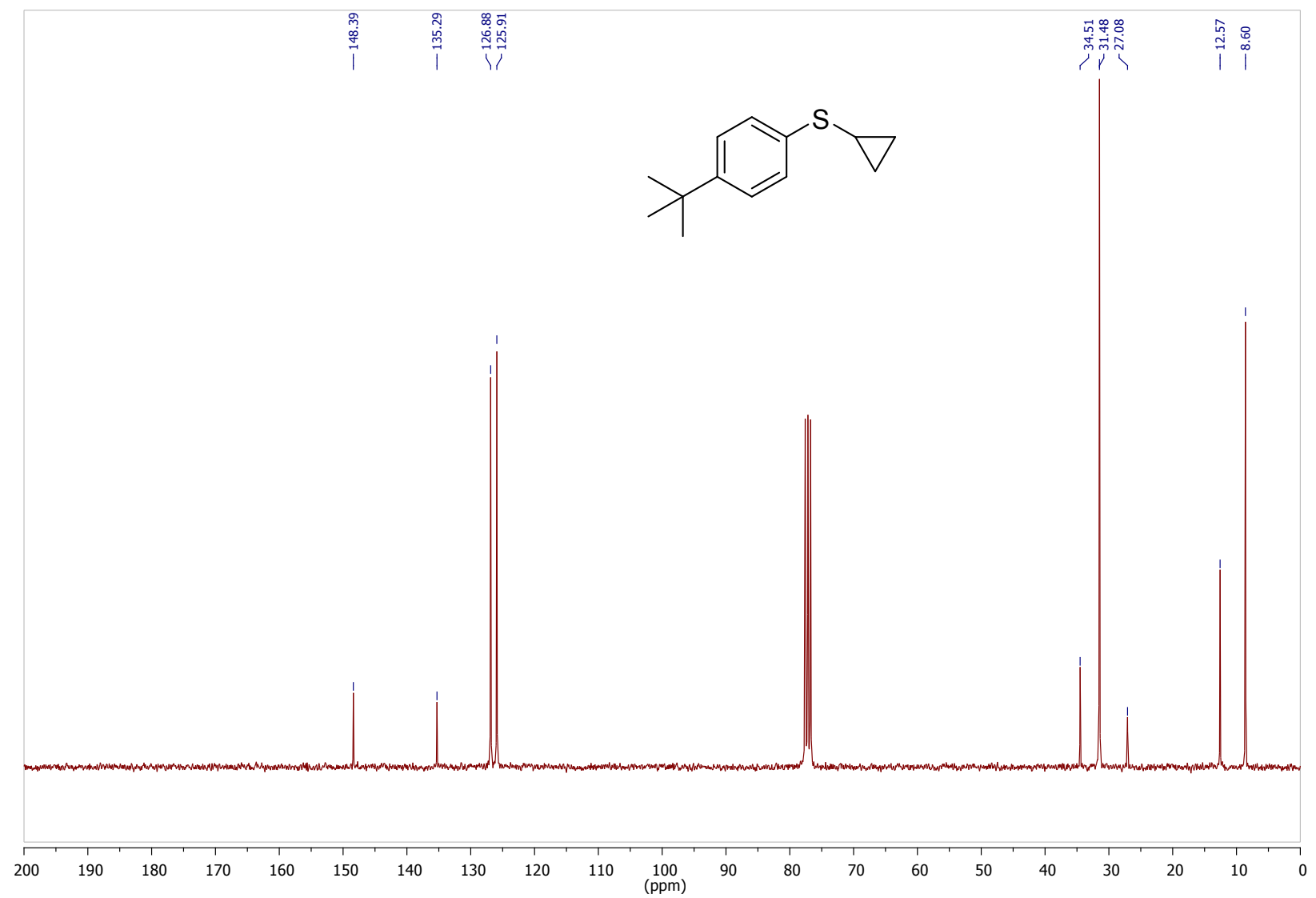


(2-Bromo-4-tert-butylphenyl)(cyclopropyl)sulfane (1h):

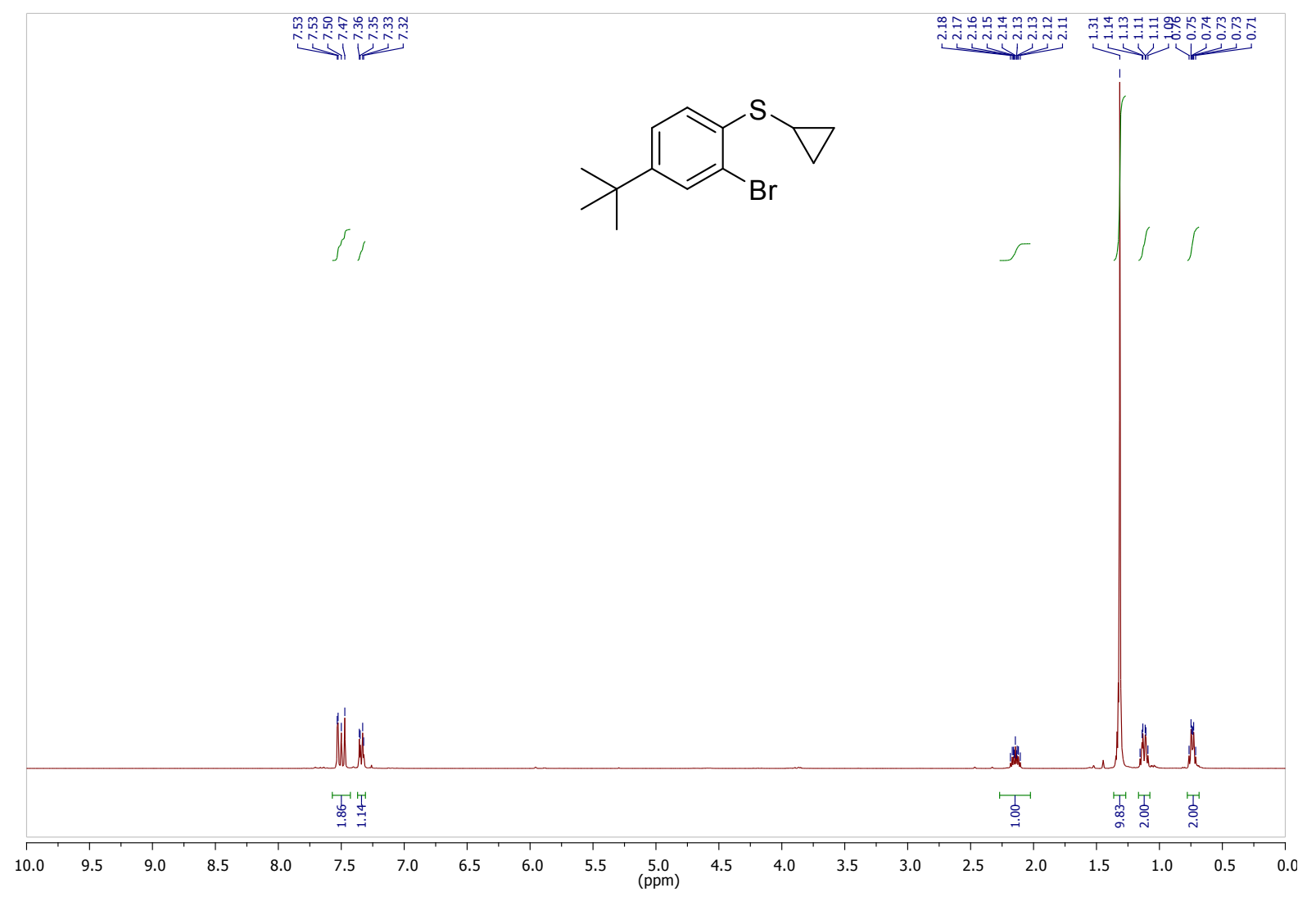




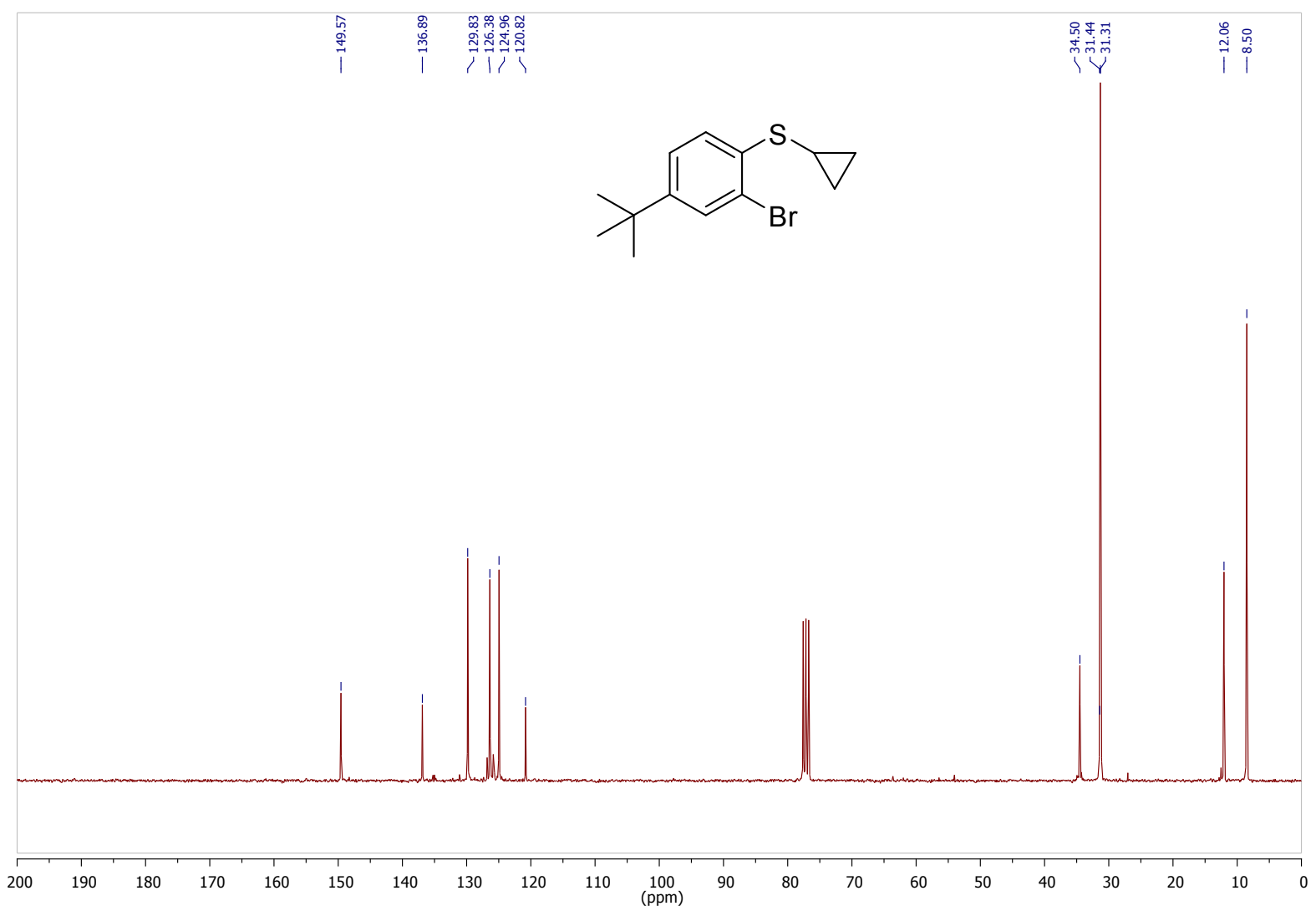




\section{Cyclopropyl(3,4-dimethoxyphenyl)sulfane:}

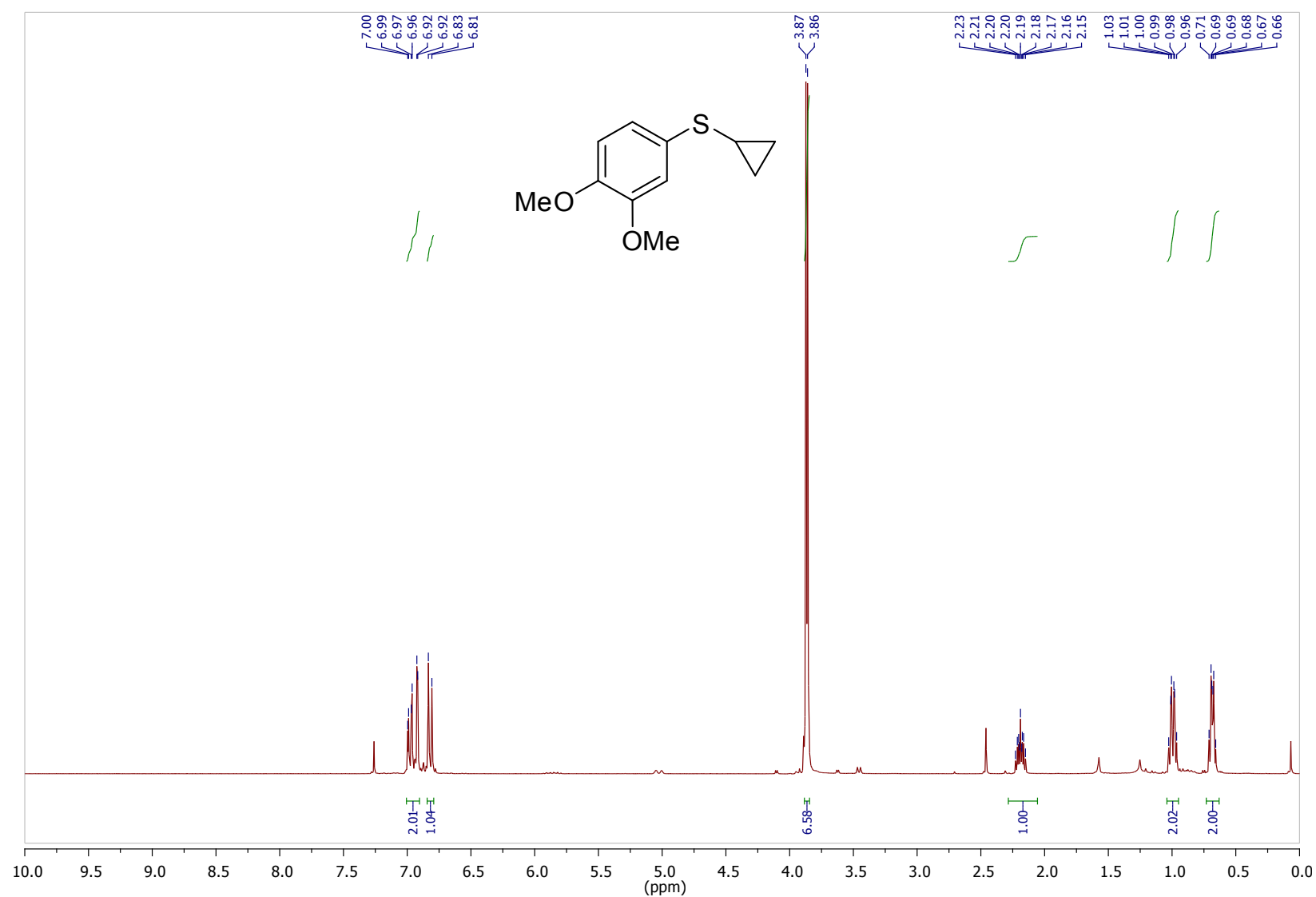




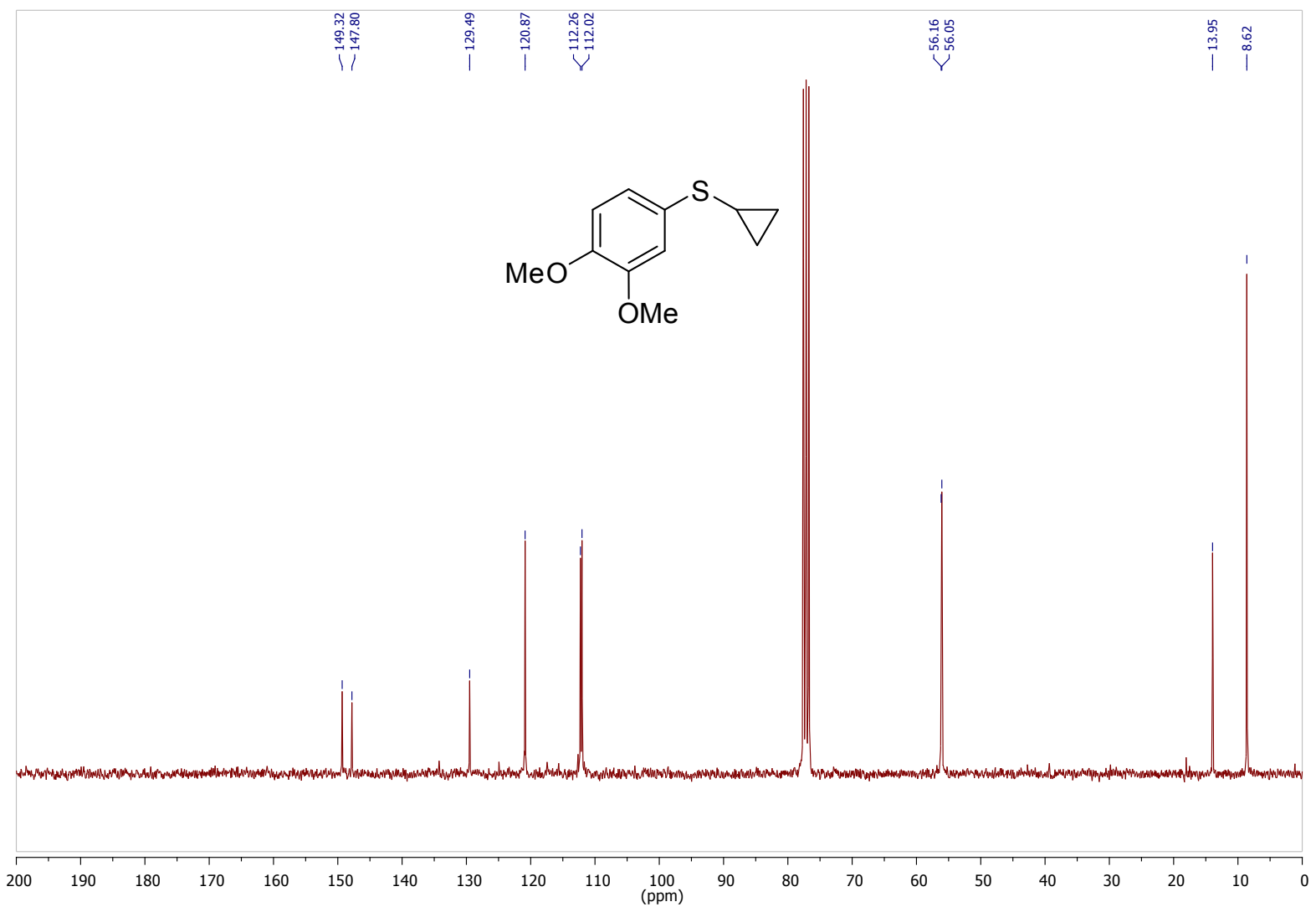


(2-Bromo-4,5-dimethoxyphenyl)(cyclopropyl)sulfane 1i:

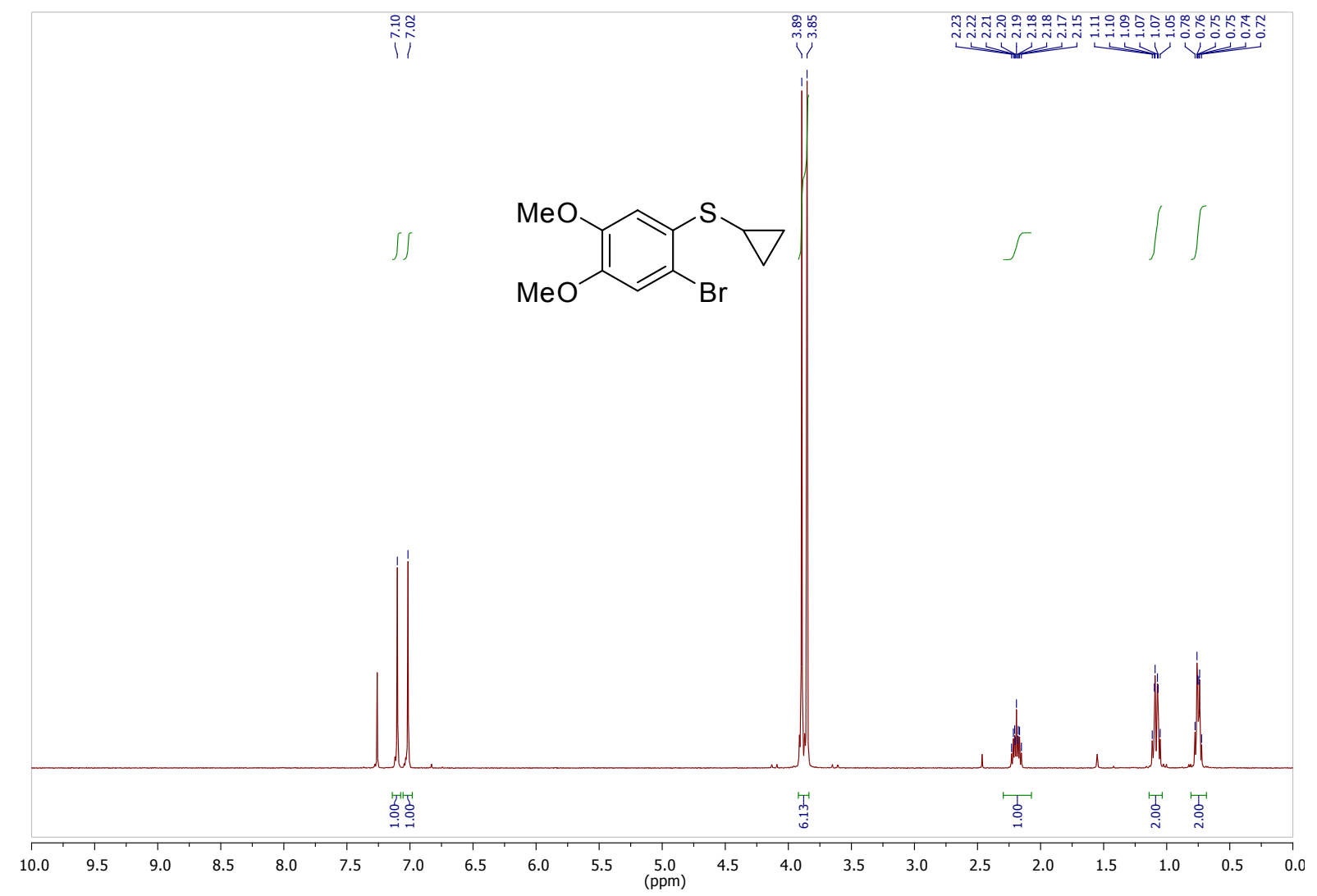




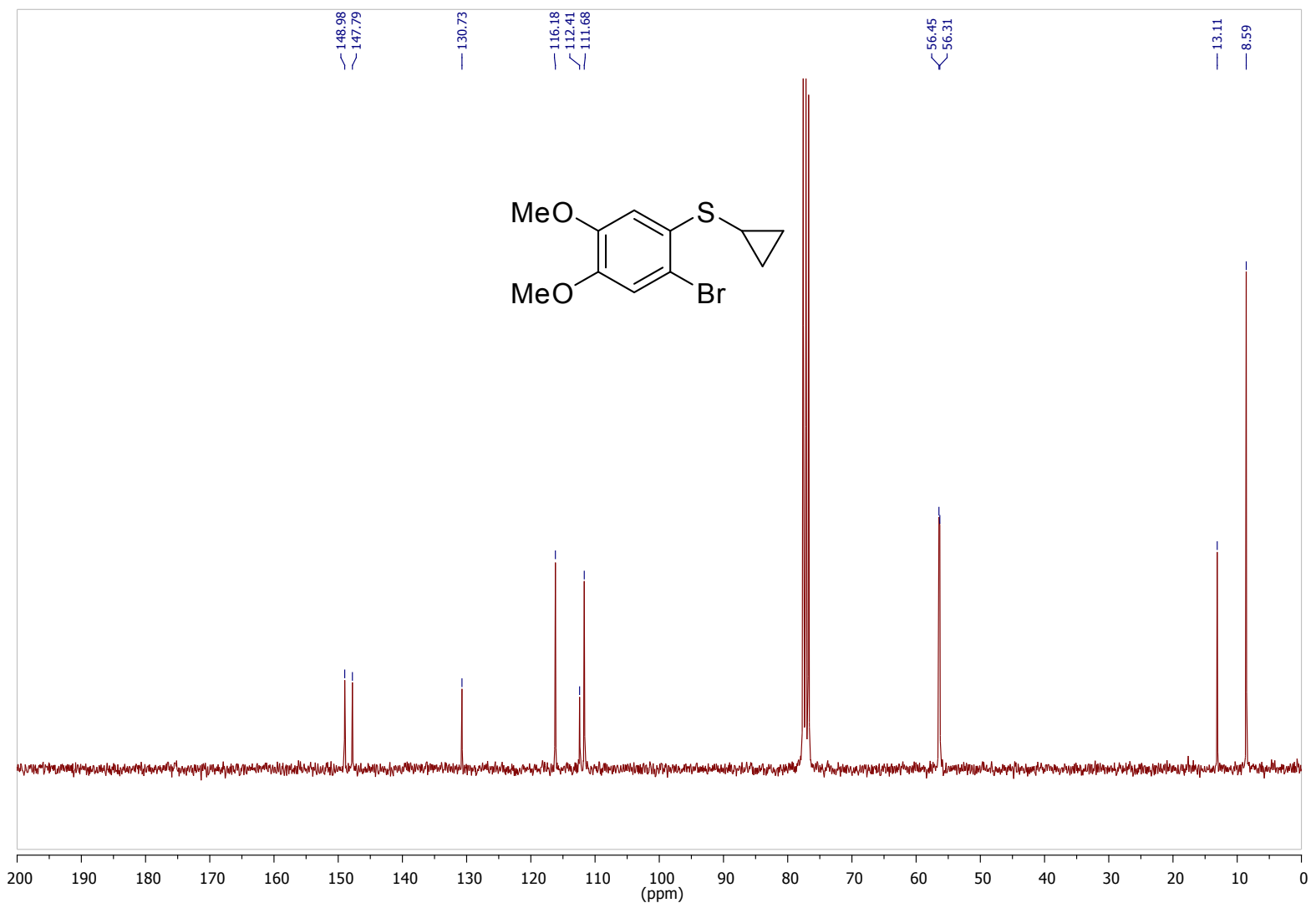


4H-Thiochromene (2a):

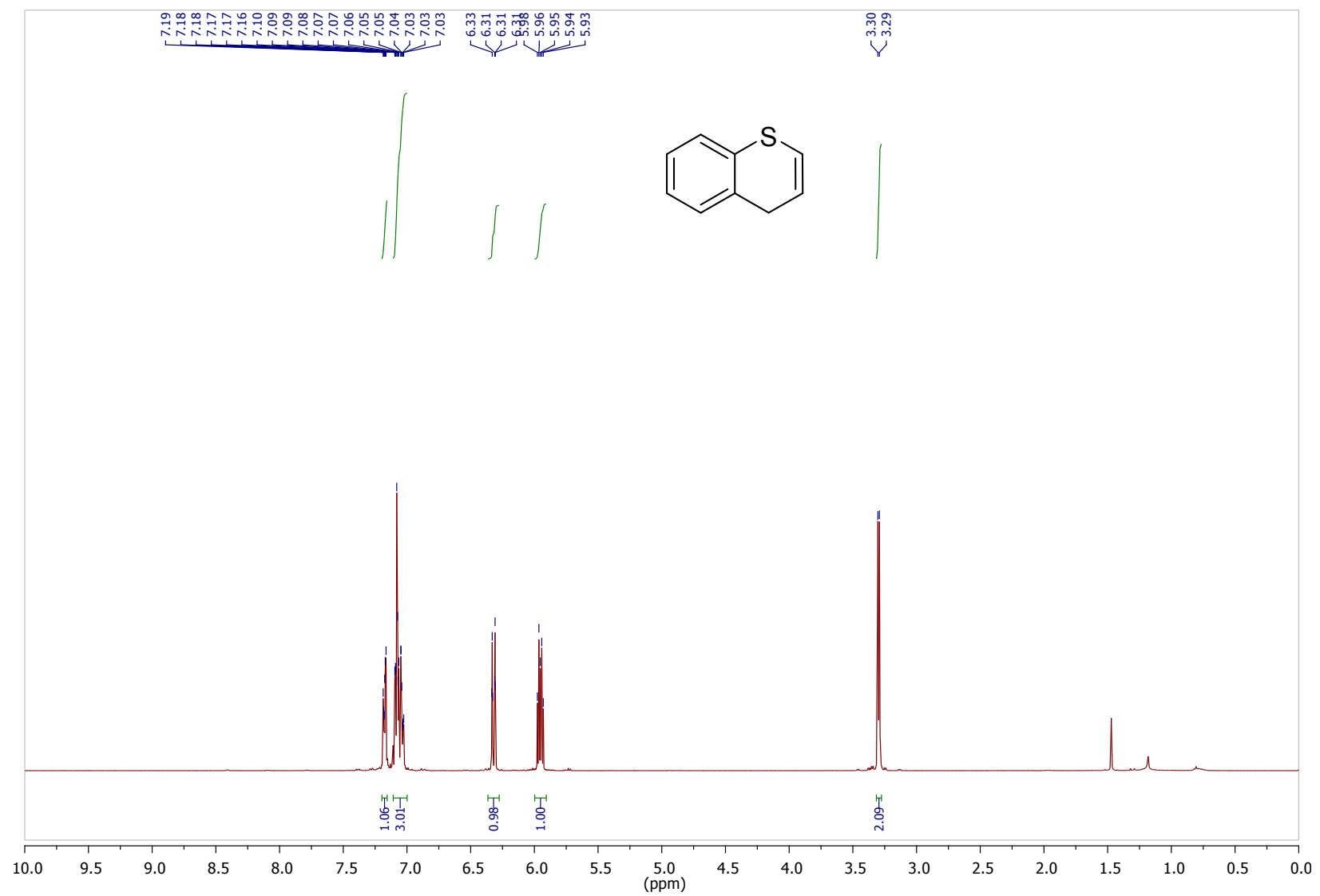




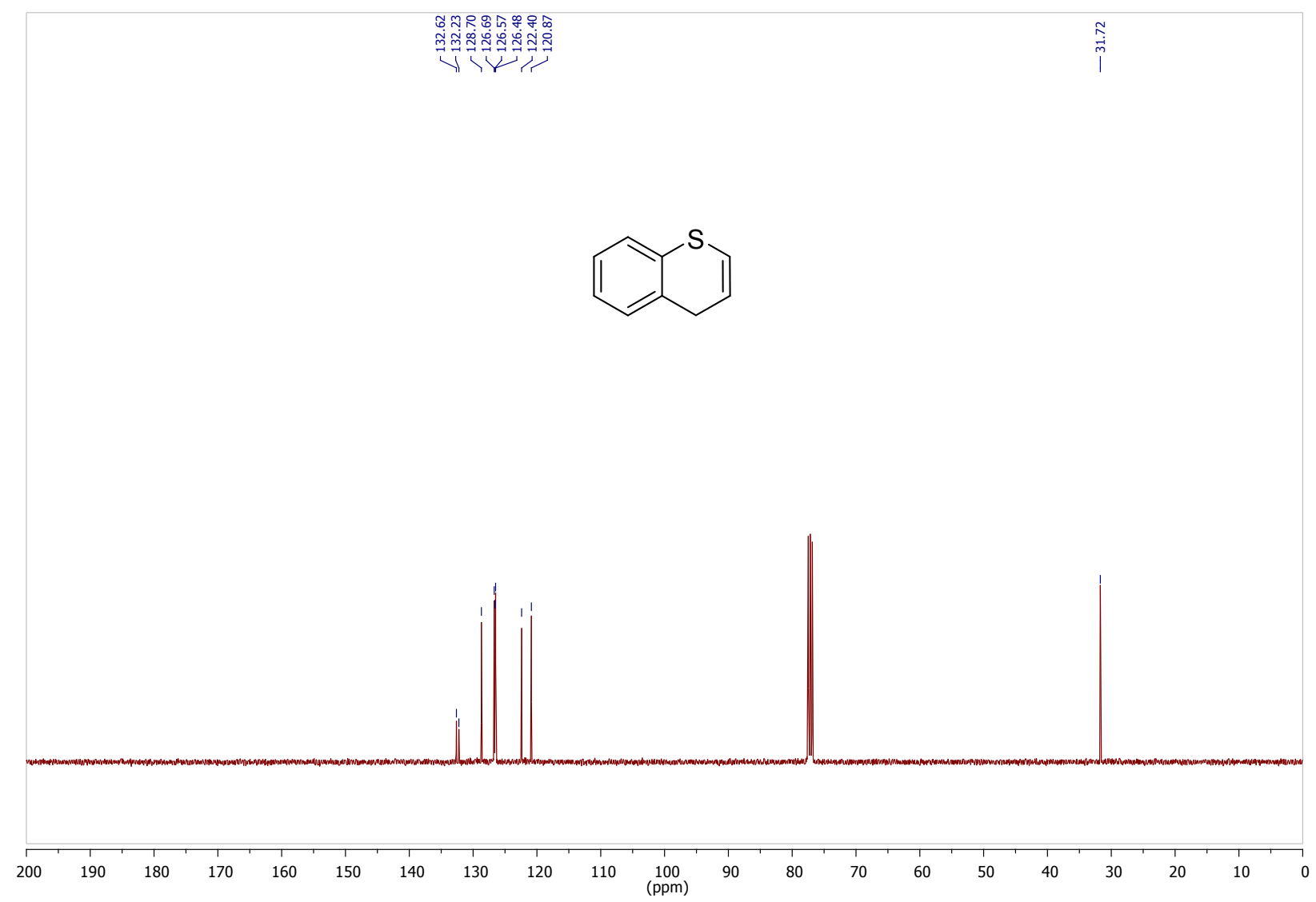


7-Chloro-4H-thiochromene (2b):

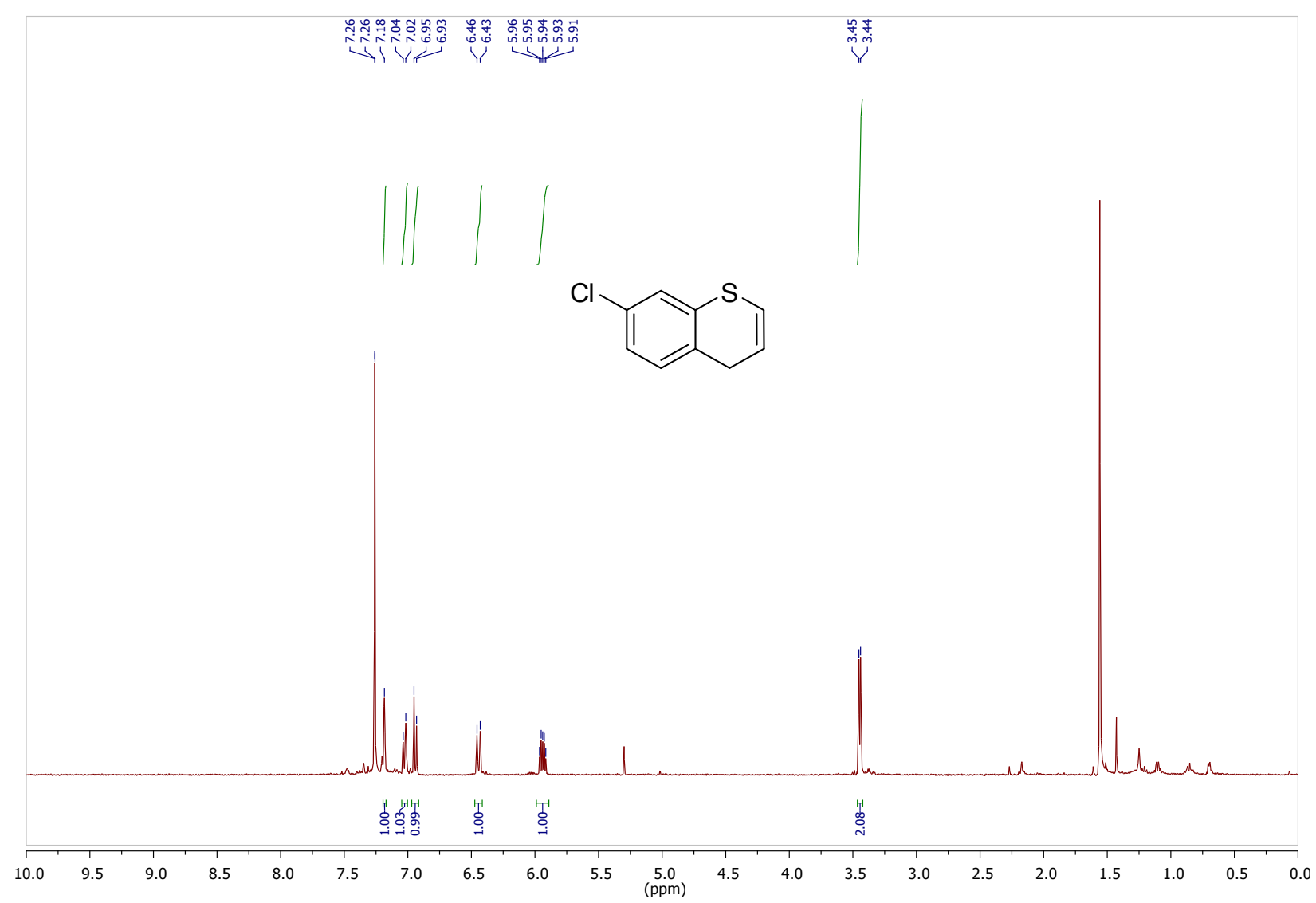




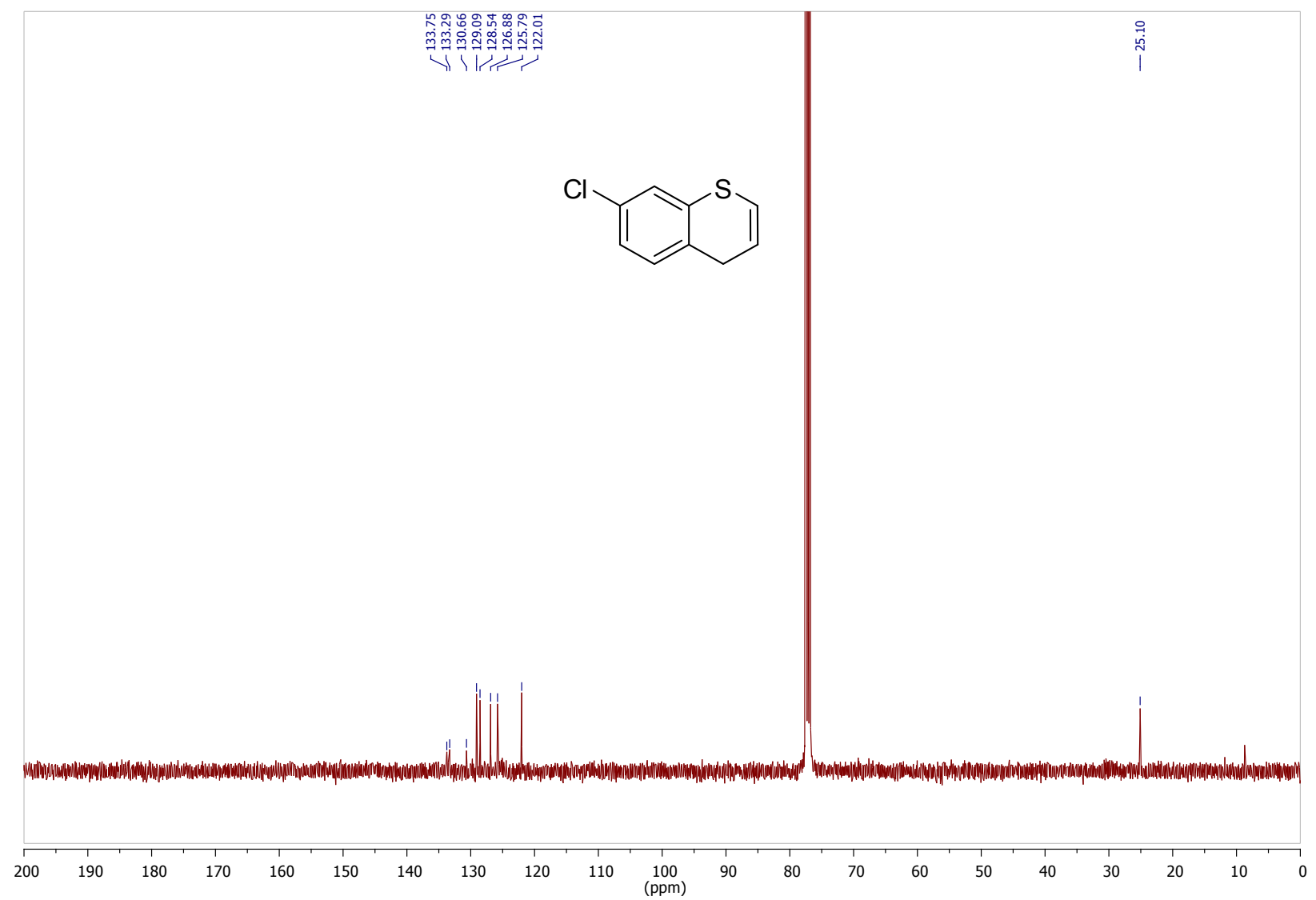

1-(4H-Thiochromen-6-yl)ethanone \& 1-(2H-thiochromen-6-yl)ethanone (2c): Starting from 1-(3-bromo-4(cyclopropylthio)phenyl)ethanone (100 mg, $0.37 \mathrm{mmol}), \mathrm{Pd}(\mathrm{OAc})_{2}(4.2 \mathrm{mg}, 0.0185 \mathrm{mmol}), \mathrm{P}^{t} \mathrm{Bu}_{3} \cdot \mathrm{HBF}_{4}(10.7 \mathrm{mg}$, $0.037 \mathrm{mmol}), \mathrm{K}_{2} \mathrm{CO}_{3}(102 \mathrm{mg}, 0.74 \mathrm{mmol})$ and following the general procedure of cyclopropane ring opening reaction, an unseparable 2.5:1 mixture of 1-(4H-thiochromen-6-yl)ethanone \& 1-(2H-thiochromen-6-yl)ethanone $2 \mathbf{c}$ was obtained as colorless oil (23 mg, 33\% yield). ${ }^{1} \mathrm{H} \mathrm{NMR}\left(400 \mathrm{MHz}, \mathrm{CDCl}_{3}\right) \delta 7.79$ (d, $J=7.3 \mathrm{~Hz}$ ), $7.67-7.51(\mathrm{~m}), 7.33$ (d, $J=7.3 \mathrm{~Hz}), 7.26-7.15(\mathrm{~m}), 6.45(\mathrm{~d}, J=10.1 \mathrm{~Hz}), 6.28(\mathrm{~d}, J=9.1 \mathrm{~Hz}), 5.97(\mathrm{dt}, J=9.1,4.7 \mathrm{~Hz}), 5.93-5.86(\mathrm{~m})$, 3.45 (d, $J=5.0 \mathrm{~Hz}), 3.37$ (d, $J=4.6 \mathrm{~Hz}), 2.49$ (d, $J=7.2 \mathrm{~Hz}) ;{ }^{13} \mathrm{C}$ NMR $\left(101 \mathrm{MHz}, \mathrm{CDCl}_{3}\right) \delta 197.4,197.3,138.9$, 135.6, 134.6, 132.5, 131.9, 128.9, 128.8, 128.5, 127.8, 127.8, 127.0, 126.5, 125.3, 122.2, 122.2, 119.9, 31.5, 26.7, 26.6, 25.3 . 


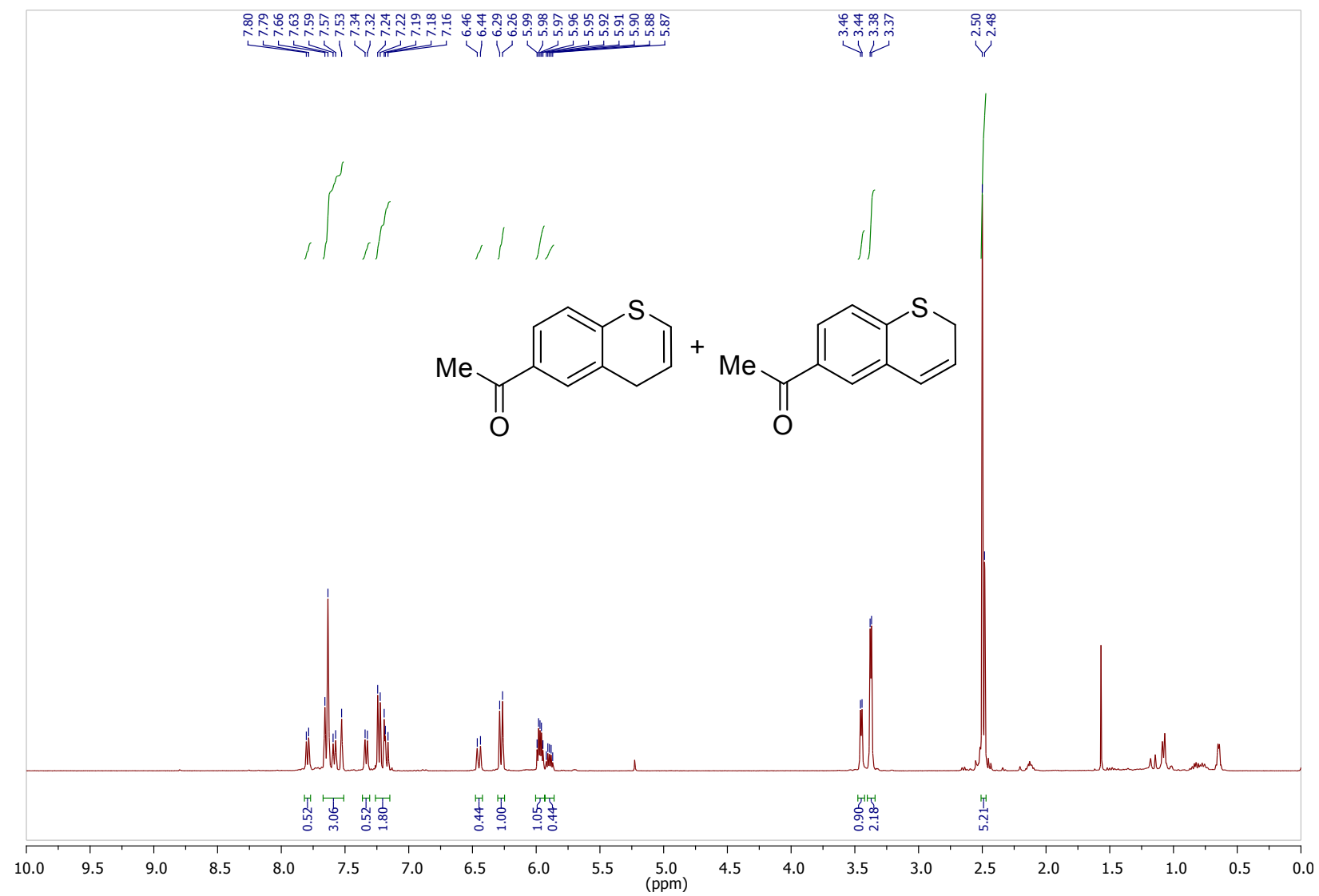




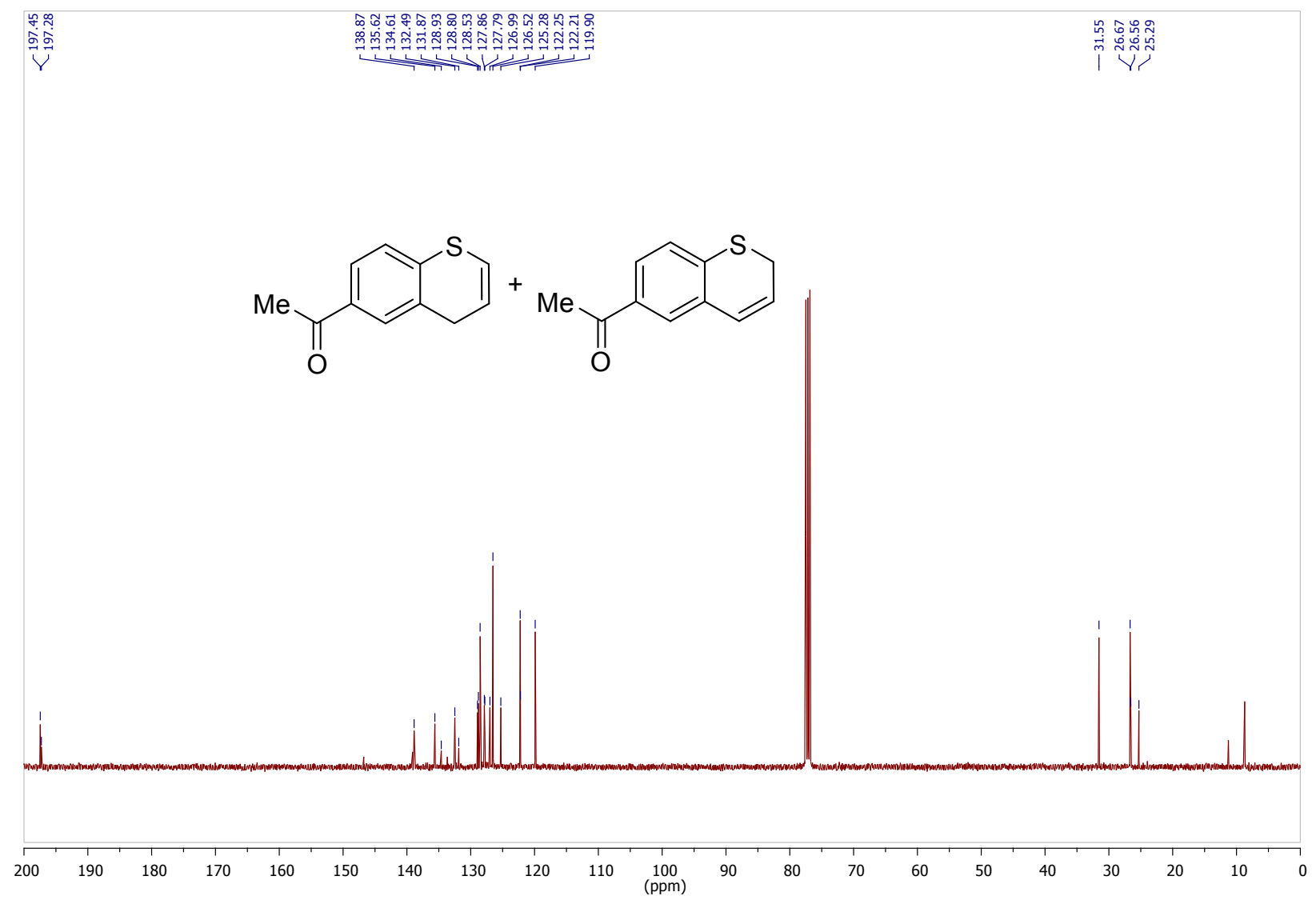


6-Methyl-4H-thiochromene (2e):

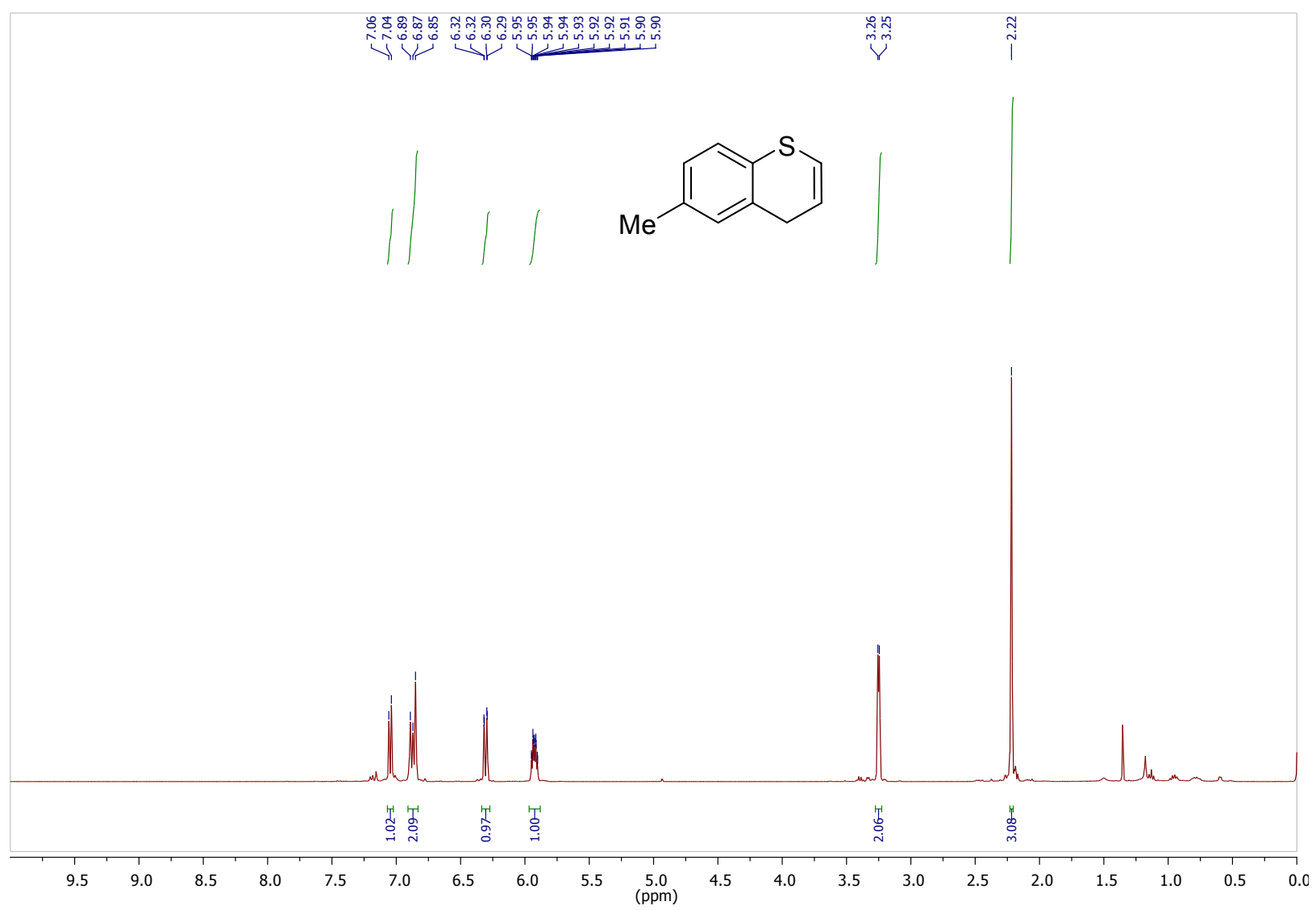




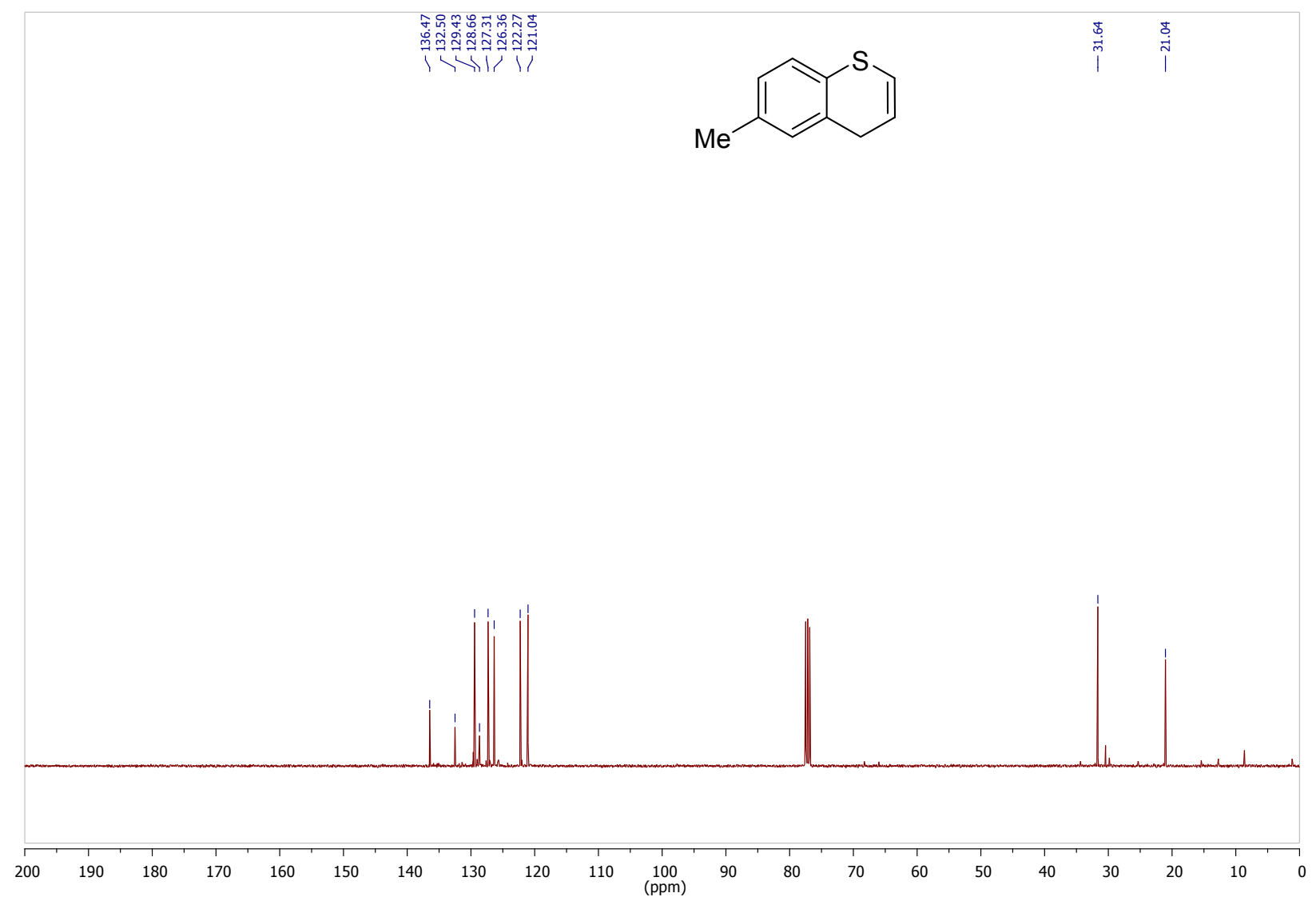


6-Ethyl-4H-thiochromene (2f):
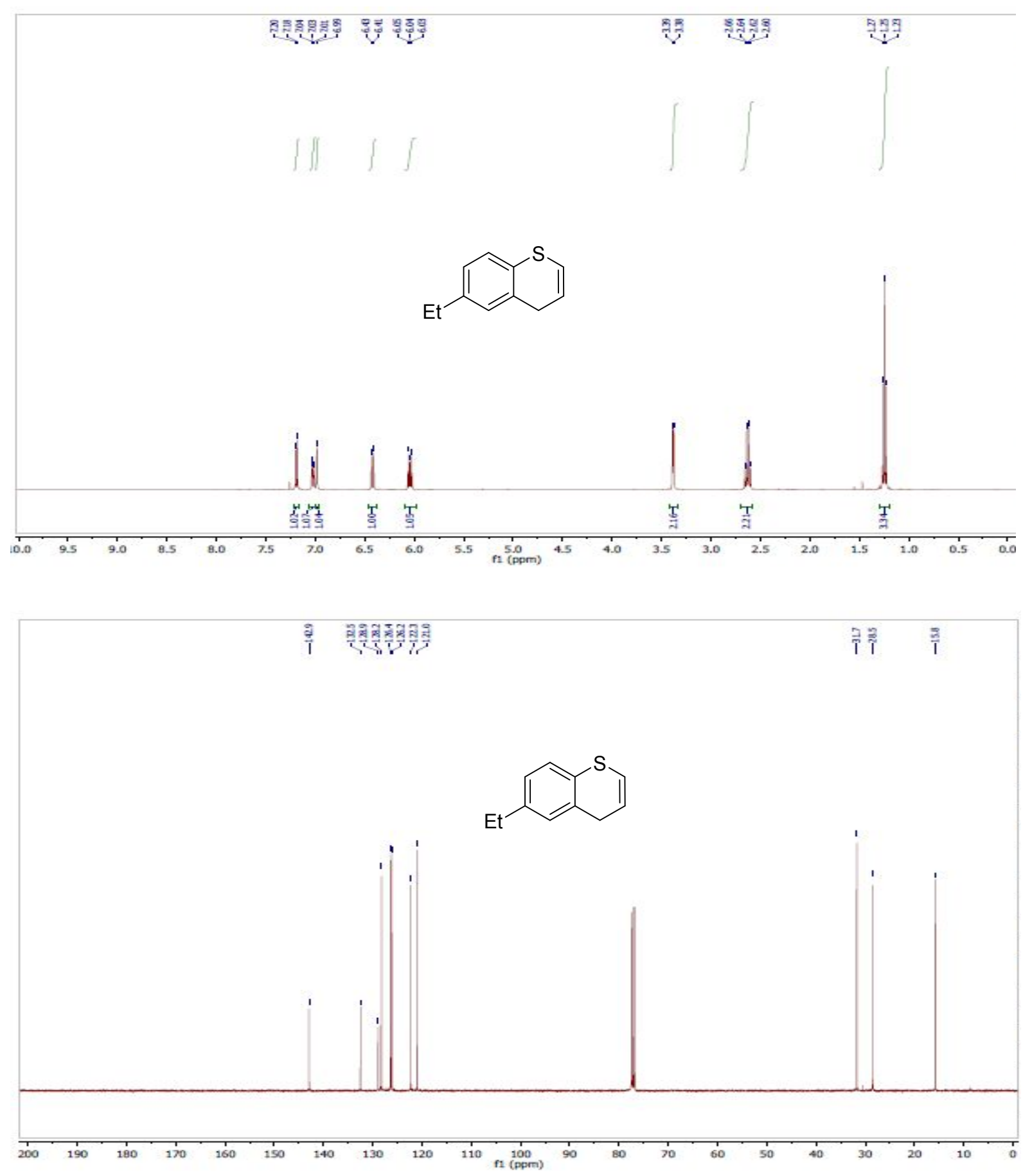
6-Isopropyl-4H-thiochromene (2g):
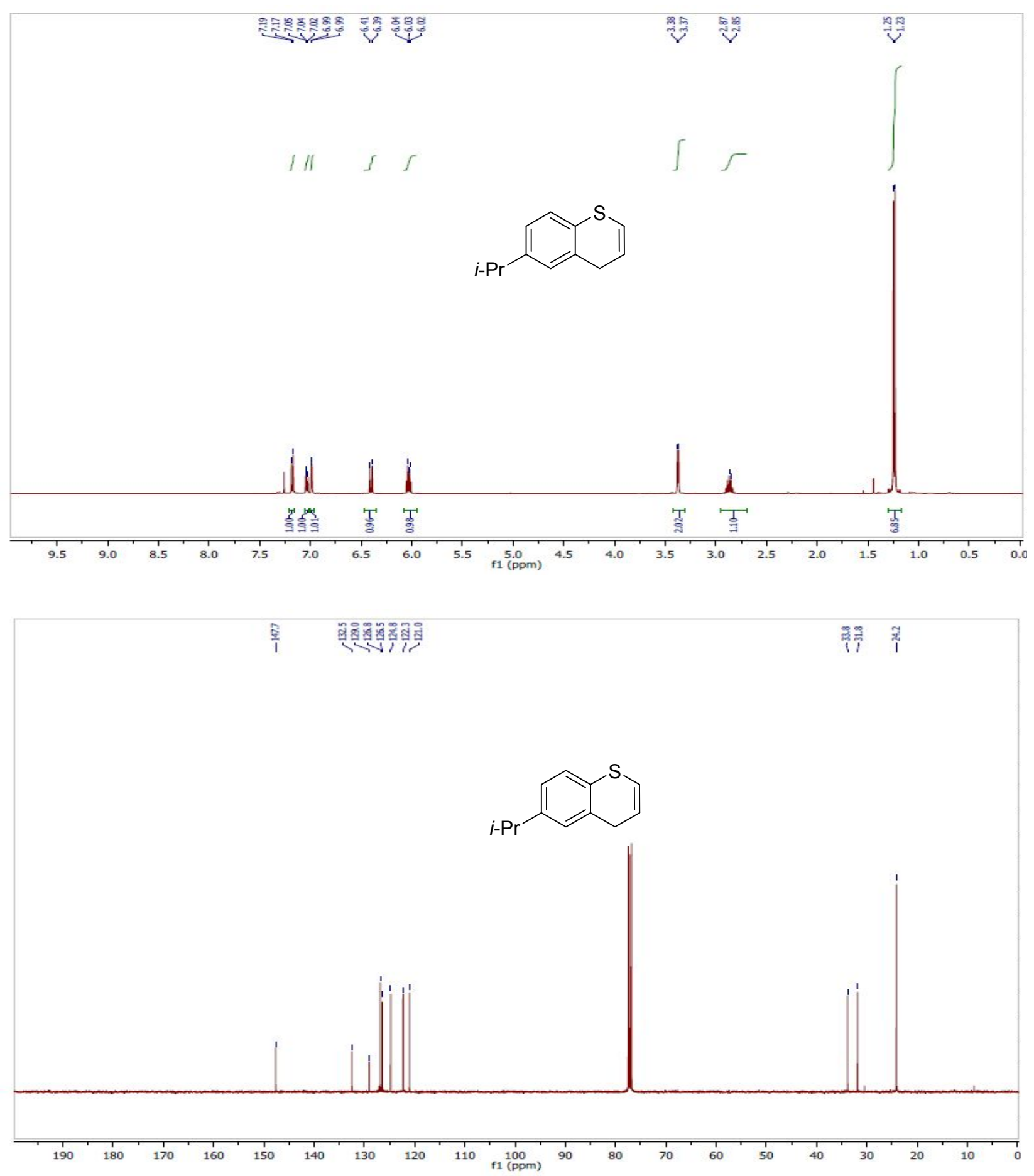

6-tert-Butyl-4H-thiochromene (2h): 


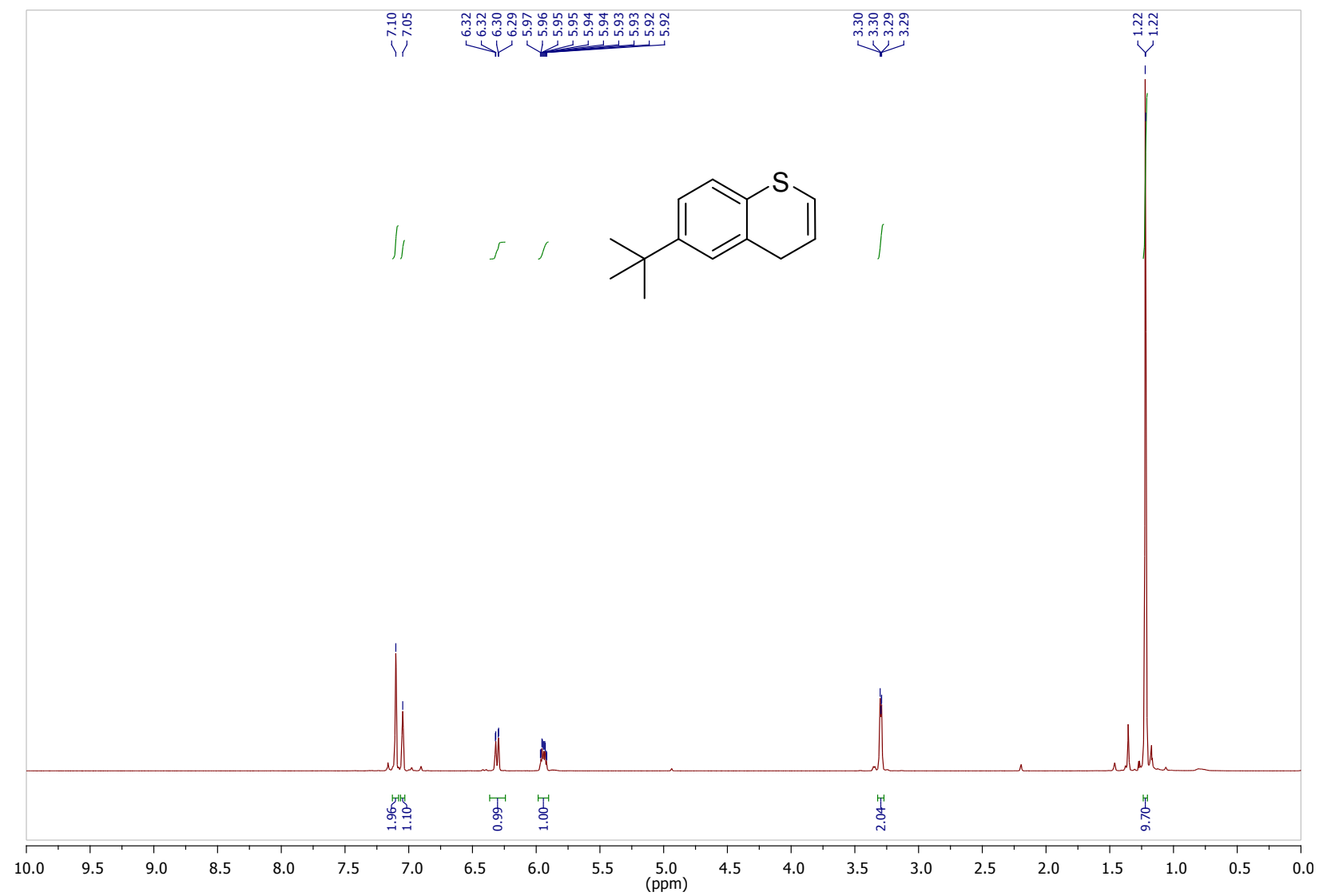




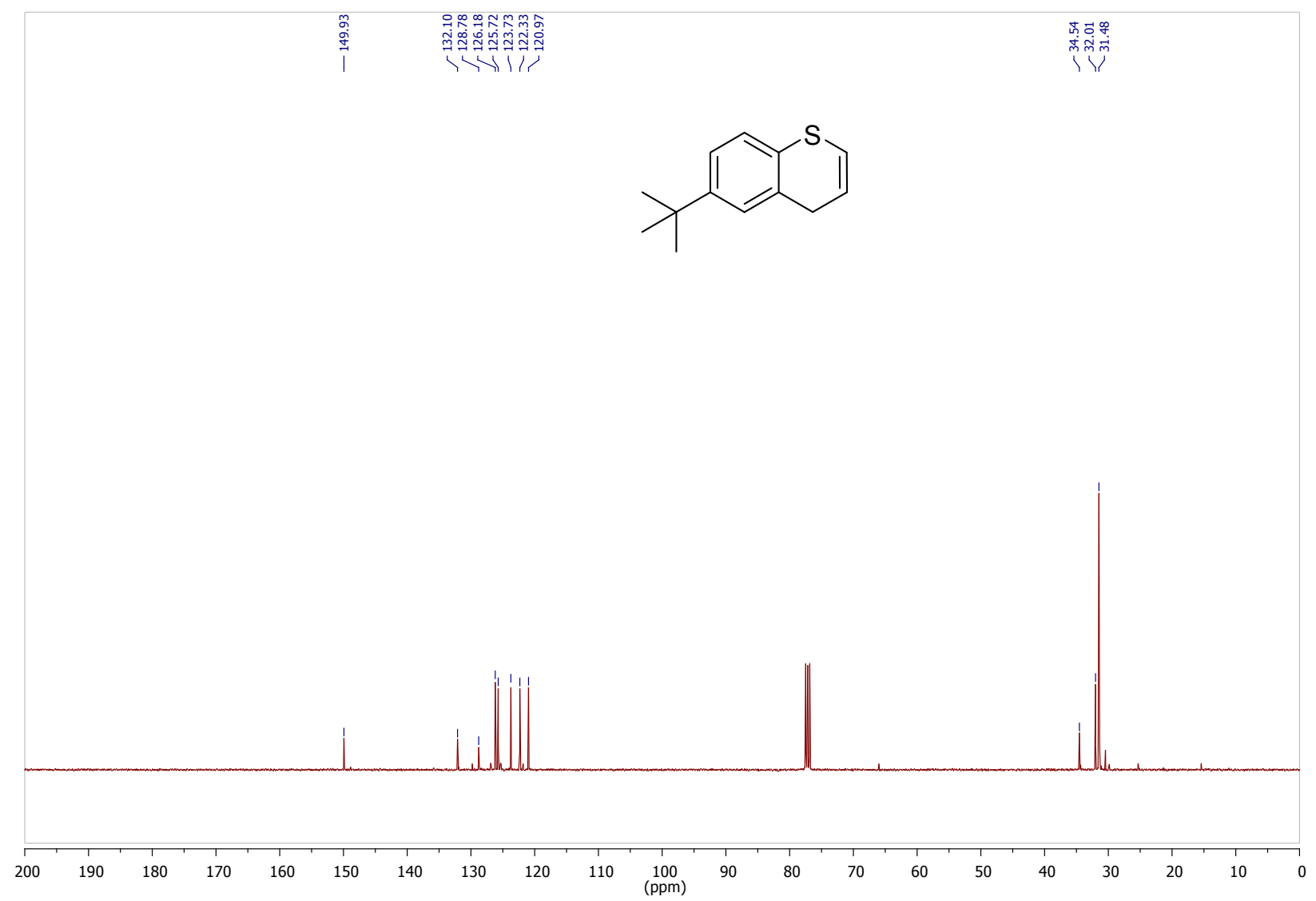


6,7-Dimethoxy-4H-thiochromene (2i):

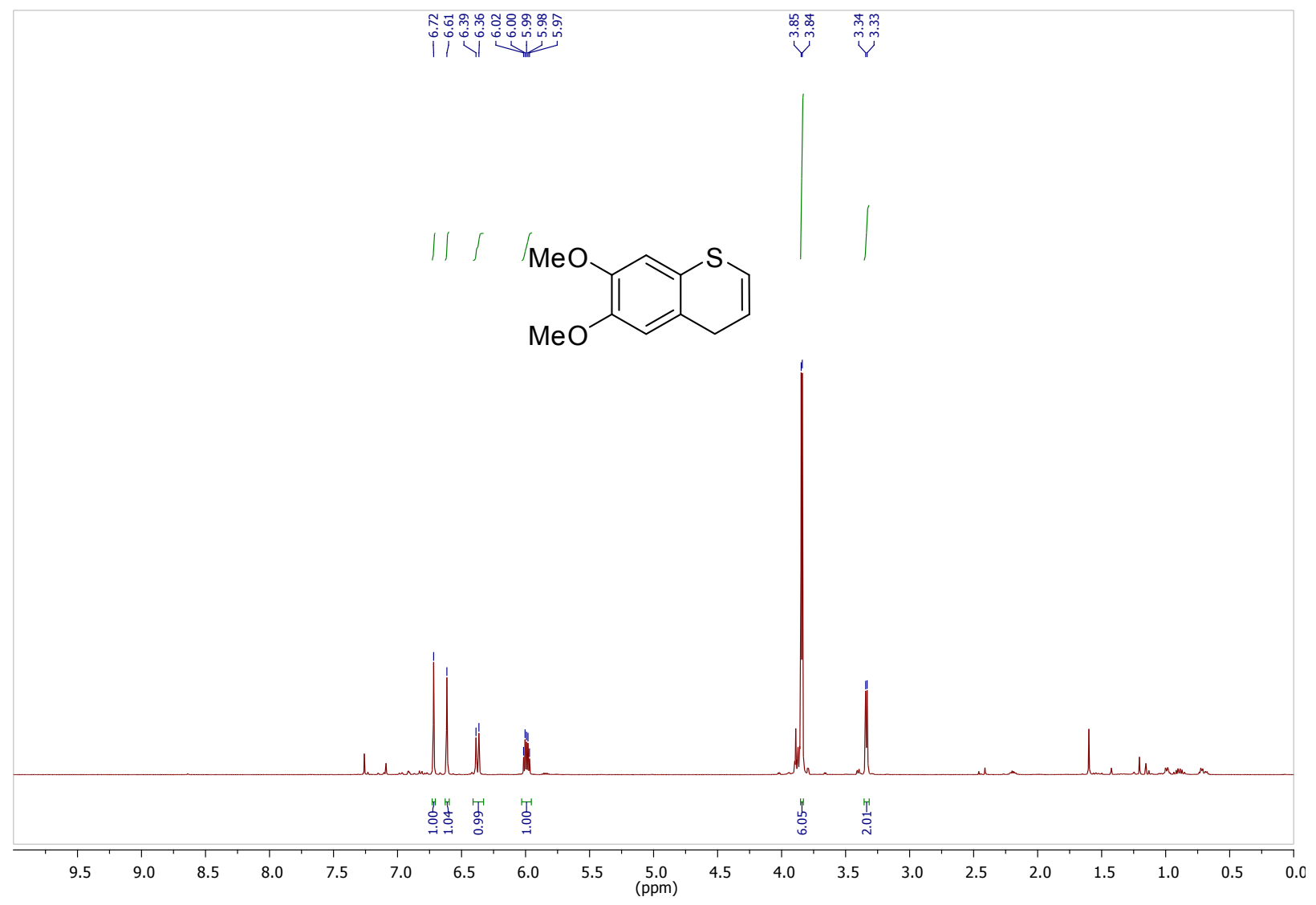




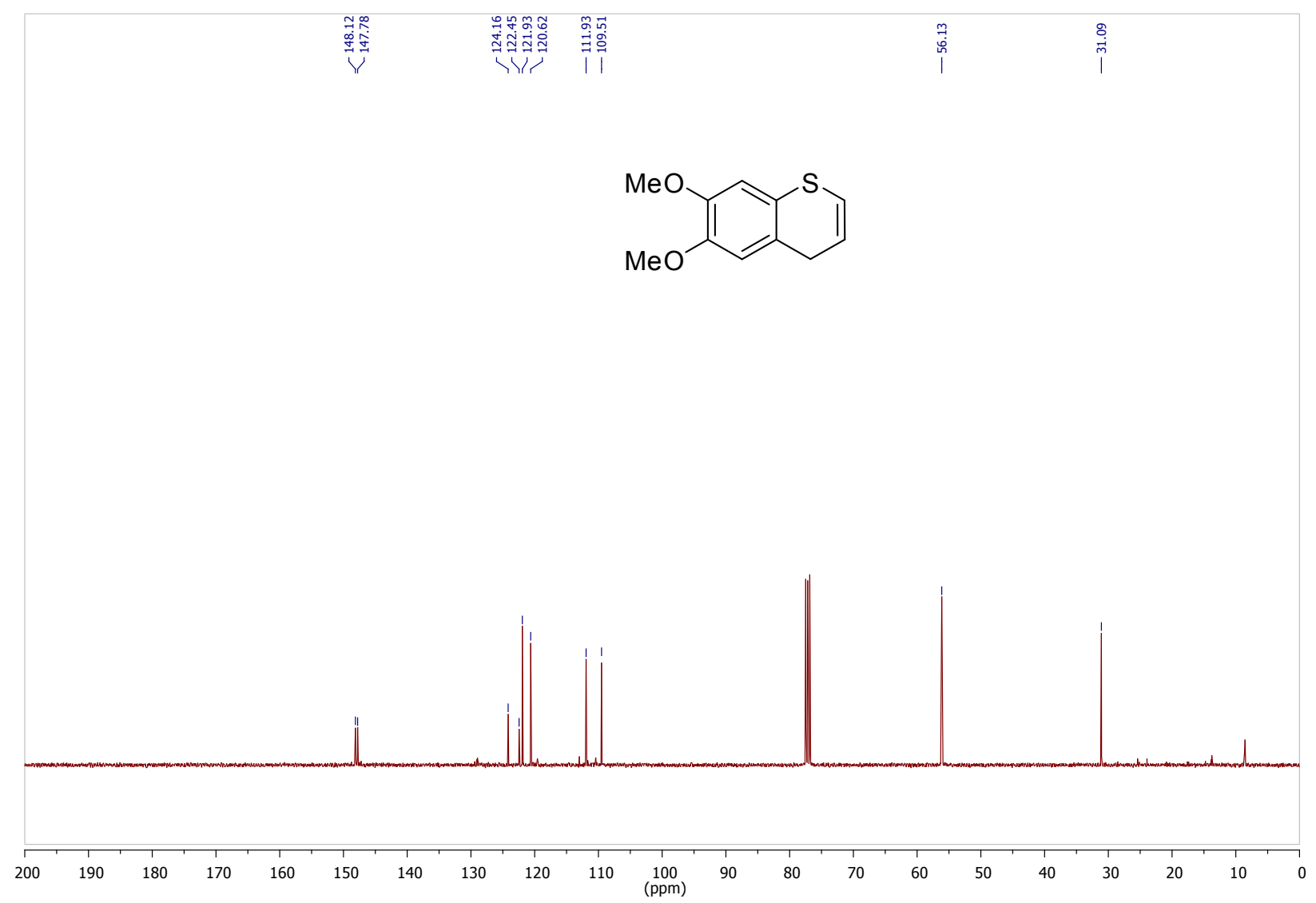

